\title{
LA POLÍTICA DE EDUCACIÓN Y FORMACIÓN DE CALIDAD COMO AMORTIGUADORA DE CRISIS ECONÓMICAS ${ }^{1}$
}

\author{
Autores: Yolanda Fernández Jurado ${ }^{2}$ \\ Profesora Propia Agregada \\ Departamento de Economía \\ Facultad de Ciencias Económicas y Empresariales \\ Universidad Pontificia Comillas
}

\section{Resumen}

En la actualidad, pocos dudan del carácter social que tiene el derecho a la educación y de la necesidad de que este Derecho Fundamental se cumpla a nivel global de la mejor forma posible; es más, desde el punto de vista económico, no se

\footnotetext{
${ }^{1}$ El presente artículo continúa la investigación sobre Un nuevo enfoque para la Política de educación y formación que la autora inició con los profesores de Comillas Susana de los Rios Sastre y Antonio Javier Ramos Llanos y que ha tenido sus antecedentes en una Comunicación realizada en las X Jornadas de Política Económica, Málaga, 20 y 21 de octubre 2011 (coautora Susana de los Rios) y en la Ponencia en el I Foro de Economía de UNIJES, Sevilla, 21 de noviembre 2014 (coautor Antonio Javier Ramos).

${ }^{2}$ yofeju@icade.comillas.edu
} 
crea ninguna controversia respecto al papel que tiene la educación y la formación en el crecimiento y desarrollo económico de los países.

Pese a esto, cuando llegan momentos de crisis económicas, existe una cierta tendencia a descuidar la política de educación y formación sin darse cuenta que ésta es un amortiguador automático para evitar los efectos negativos que se generan con estas crisis

En el presente artículo se analizará cómo ha ido evolucionando la Política de educación y formación desde una Política Social, con una visión destinada al cumplimiento de un Derecho Fundamental, hasta una visión económica en la que la educación y la formación, junto con la posible investigación, desarrollo e innovación, son instrumentos fundamentales para el crecimiento y desarrollo económico.

Además, se expondrá en qué medida la educación y formación han ido cobrando importancia dentro del ámbito económico. Para analizar esta evolución se comprobará la evolución que ha tenido en la Unión Europea la política de educación y formación, ya que es uno de los entornos en los que más claramente se observa cómo esta política ha pasado de ser un instrumento complementario para lograr algunos objetivos económicos, a considerarse uno de los pilares fundamentales en la nueva Estrategia europea.

Por último, para afianzar la importancia que tiene esta política, se destaca un aspecto poco considerado en relación con la educación y formación: es amortiguadora de crisis económicas. Esta función no se suele tener en cuenta cuando se habla de políticas anticrisis de corto plazo; sin embargo, es fundamental considerarla ya que puede evitar muchos de los efectos socioeconómicos negativos que se producen en situaciones. Este carácter amortiguador dota a la Política de educación y formación, especialmente la de calidad, de un nuevo papel dentro de las Políticas Socioeconómicas que se aplican tradicionalmente en los países y exige una reconsideración del lugar que la misma ocupa dentro de éstas.

Palabras clave: Política de educación y formación; Política de investigación, desarrollo e innovación; capital social; capital humano; capital tecnológico; crecimiento y desarrollo económico; crisis económicas.

\title{
The policy education and training of quality as dampening economic crises.
}

\begin{abstract}
Today, few doubt the social character who has the right to education and the need that this fundamental right is met at the global level in the best possible way; moreover, from the economic point of view, does not create any controversy regarding the role that the education and training on growth and economic development of countries.
\end{abstract}


Despite this, when moments of economic crisis, there is a tendency to neglect education policy and training without realizing is that this is an automatic damper to prevent the negative effects that are generated with these crises.

This article will discuss how evolved the policy of education and training a Social policy, with a view to the fulfilment of a fundamental right, to an economic vision that education and training, along with the possible research, development and innovation, they are fundamental instruments for growth and economic development.

In addition, education will be exposed to what extent and training have been gaining importance within the economic sphere. To analyze this issue will prove the evolution that has taken in the European Union policy of education and training, as it is one of the environments in which more clearly shows how this policy has gone from being a complementary tool to make some economic objectives, considered to be one of the fundamental pillars in the new European strategy.

Finally, to reinforce the importance that has this policy stands an aspect little considered in relation to education and training: dampens economics crises. This function is not usually take into account when he speaks of policies anti-crisis short-term. However, it is essential to consider it since you can avoid many of the negative socio-economic effects that occur in these crisis situations. This cushion character gives to education policy and training, especially for quality, a new role within the socio-economic policies that apply traditionally countries and requires a reconsideration of the place the same within these.

Key words: education policy and training; research, development and innovation policy; social capital; human capital; technological capital; economic growth and development; economic crises.

\section{LA EDUCACIÓN Y LA FORMACIÓN COMO DERECHO FUNDAMENTAL E INSTRUMENTO ECONÓMICO}

Desde que en 1948 la Declaración Universal de Derechos Humanos de las Naciones Unidas expuso con toda claridad, en su artículo 26.1 que "toda persona tiene derecho a la educación (...) La instrucción técnica y profesional habrá de ser generalizada; el acceso a los estudios superiores será igual para todos, en función de los méritos 
respectivos." 3 , la educación y la formación se han considerado un Derecho Social básico lo que explica que su importancia se haya ido destacando en diversos Acuerdos o Declaraciones Internacionales durante el siglo XX y lo que se lleva del XXI.

Por otro lado, además de ser un Derecho, desde 1945 ya se había puesto de manifiesto la importancia que tiene la educación y la formación como un instrumento para lograr un adecuado desarrollo económico de los países.

Si bien los economistas clásicos y neoclásicos tenían una clara tendencia a considerar como factores productivos la tierra, el capital y el trabajo y valoraban el desarrollo de la economía relacionándolo con la adecuada gestión de los mismos, de forma que los aumentos de producción fueran buenos tanto para las empresas como para el país; en la primera mitad del siglo XX se puso de manifiesto que esto no era tan sencillo.

En el desarrollo económico de un país influyen muchos factores lo que hizo necesario valorar qué se puede considerar factor productivo, analizar si tiene o no externalidades (positivas o negativas), cómo se puede mejorar su productividad, si es mejor desarrollarse con economía cerrada o abierta, en libre mercado o de la mano del Sector Público, etc. Todas estas cuestiones abrieron un importante debate teórico que estaba dando pocos resultados prácticos ya que en los tradicionales modelos de desarrollo económico apenas se valoraba el factor humano y las consecuencias sociales y ambientales que dicho desarrollo podría tener.

Aunque desde su creación la Organización de Naciones Unidas ha tenido entre uno de sus mandatos el desarrollo económico y social y ha promovido importantes acciones destinadas a fomentarlo, especialmente desde que creó en 1965 el Programa de las Naciones Unidas para el Desarrollo (PNUD); los desequilibrios existentes en los países desarrollados, los fracasos en algunos procesos de desarrollo y las fuertes desigualdades territoriales que había, ponían de manifiesto que algo no se estaba planteando adecuadamente.

Hasta la década de los años noventa nadie dudaba que la educación y la formación favorecían la creación de capital humano, lo que permitía mayor productividad del factor trabajo y más posibilidades para la investigación, el desarrollo y la innovación (lo que favorecería el factor productivo tecnológico) contribuyendo claramente al crecimiento económico y si, además, se establecía la enseñanza básica obligatoria y gratuita se podían reducir posibles situaciones de exclusión social, lo que garantizaría las mismas oportunidades a todos los ciudadanos, lo que a su vez podría fomentar un adecuado desarrollo del país.

El concepto de desarrollo económico sufrió cierta alteración a partir de los años noventa con las aportaciones de autores como A. K. Sen ${ }^{4}$ (2000) quien

\footnotetext{
${ }^{3}$ Véase: http://www.derechoshumanos.net/normativa/normas/1948-DeclaracionUniversal.htm

${ }^{4}$ Autor que desarrolla el concepto de Bienestar Humano, en el que el desarrollo de capacidades del individuo y la mayor libertad para aplicarlas son factores fundamentales para el desarrollo de las naciones. Ver A. Sen, 2000, pp. 114-141.
} 
destacó el concepto del desarrollo humano ${ }^{5}$, dando lugar al nacimiento de una nueva visión en el desarrollo de los países: desarrollo socioeconómico sostenible.

En este nuevo contexto, la educación y la formación dejan de ser un instrumento para crear capital humano o desarrollar capital tecnológico para convertirse en uno de los objetivos básicos en el desarrollo económico; de hecho, es uno de los Objetivos del Milenio establecidos por las Naciones Unidas en el año 2000.

La educación permite el desarrollo de capacidades, habilidades y valores. La formación permite el perfeccionamiento y la ampliación de esta base a lo largo de la vida, favoreciendo la posibilidad de una mejora continua gracias a la creación y transmisión de conocimiento. Por tanto, se puede afirmar que en esta nueva visión es donde la educación y formación cobran una nueva dimensión dado que permiten: crecimiento económico, inclusión social, mayor conciencia respecto a la sostenibilidad medioambiental y, en definitiva, desarrollo socioeconómico sostenible.

\subsection{Crecimiento económico}

Una educación y formación amplia y de calidad favorece un mayor y mejor capital humano; mejores posibilidades para el desarrollo de capital tecnológico, gracias al posible aumento en investigación, desarrollo e innovación $(\mathrm{I}+\mathrm{D}+\mathrm{i})$ y mejor capital social, tanto a nivel microeconómico como macroeconómico. Teniendo en cuenta que se produce un aumento de tres de los factores productivos fundamentales en un país, parece razonable que se pueda producir un incremento en el Producto Interior Bruto (PIB) de una nación.

Un mayor conocimiento y una mejor transmisión del mismo fomentan la aparición de nuevas producciones de bienes y servicios y la búsqueda de nuevos nichos de mercado. La capacidad de nuevas interrelaciones y de mentalidades más abiertas a las novedades permite nuevos contactos empresariales intra e internacionales, lo que favorece la innovación en los sectores y en la estructura empresarial de los países. Todo esto favorece el lado de la Oferta Agregada de la economía y aumenta las posibilidades de generación de renta.

\footnotetext{
${ }^{5}$ Sus aportaciones son la base de la creación en el PNUD del Índice de Desarrollo Humano (IDH) que se ha convertido en un punto de referencia básico para el análisis de la evolución de los países.
} 
Figura 1. La Educación y Formación en el Crecimiento Económico

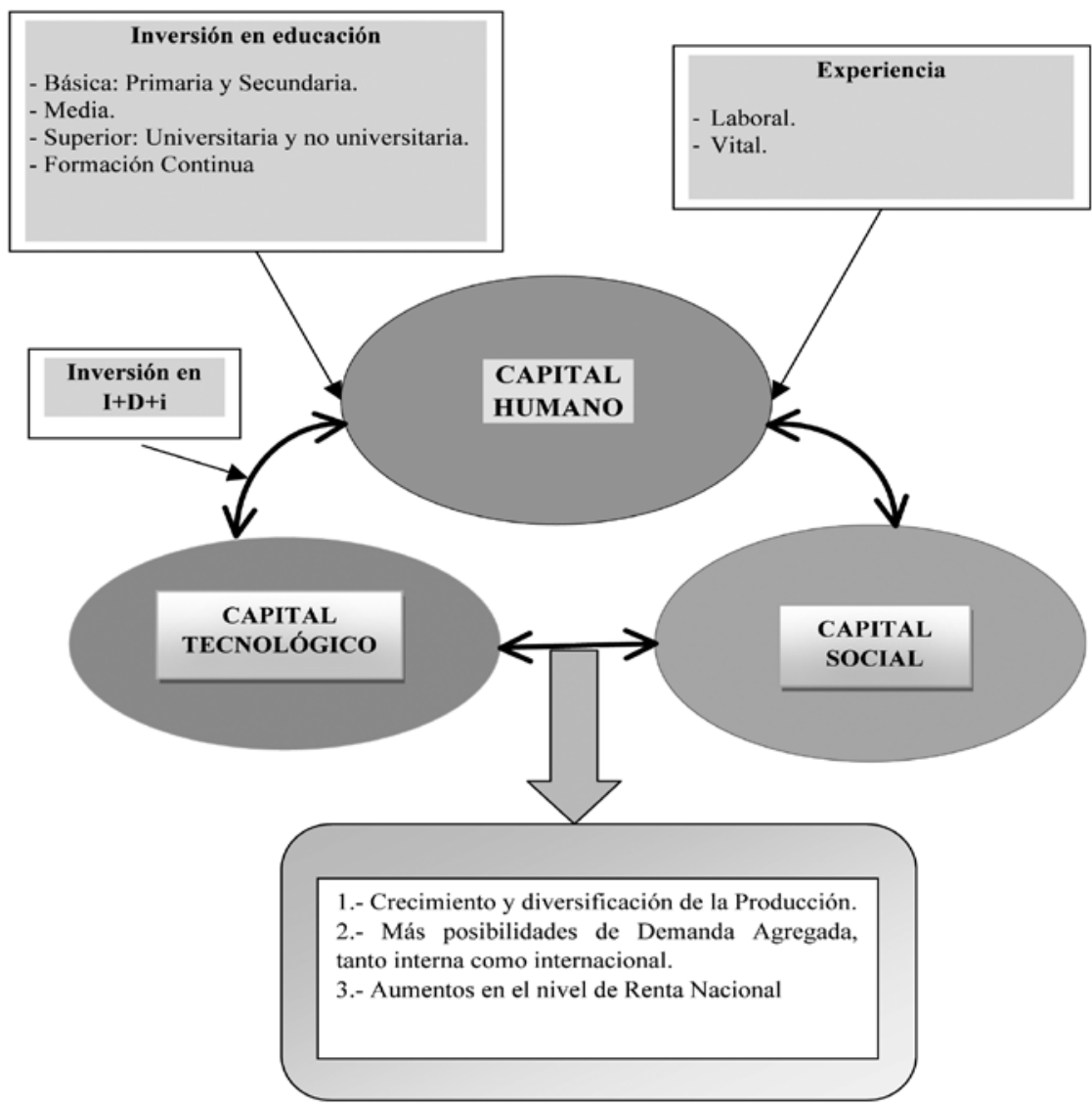

Fuente: elaboración propia.

Pero de nada serviría que aumentara el lado de la Oferta si no le acompañara en el proceso la Demanda Agregada de la economía. En este sentido, la educación y la formación también juegan un papel fundamental:

- En primer lugar, según el informe El Desarrollo Sostenible empieza por la Educación de la UNESCO (2014), se puede confirmar que gracias a una adecuada educación se puede optar a un sueldo mayor y, por tanto, las familias podrían disponer de más capacidad para consumo y ahorro.

- En segundo lugar, al disponer de mejor educación y formación se pueden canalizar más adecuadamente los recursos financieros existentes hacia las inversiones productivas más adecuadas para el país. Además si se ha fomentado la investigación, desarrollo e innovación, esas inversiones se pueden 
dirigir hacia sectores competitivos a nivel internacional. Todo esto puede mejorar la Formación Bruta de Capital del país e influir favorablemente en, como mínimo, la Balanza Comercial del mismo.

- En tercer lugar, una mejor preparación de los individuos puede aumentar la capacidad para gestionar más eficazmente las empresas y adaptar los sistemas productivos al contexto de globalización existente, lo que posicionaría al país en una situación económica internacional más favorable y facilitaría las relaciones económicas entre países.

En definitiva, una adecuada educación y formación puede permitir un crecimiento del PIB y de la Demanda Agregada, lo que posibilitaría generar más renta en la economía (Figura 1). Si además esta mayor renta se distribuyese adecuadamente, se podría afirmar que se entra en un proceso de desarrollo económico que fortalecería no sólo a la economía sino a toda la sociedad del país.

\subsection{Inclusión Social}

Disponer de una educación y formación adaptadas a las necesidades de la sociedad permite que los individuos entren a participar más de la misma tanto a nivel económico como social.

Si una persona está formada, dispone de más posibilidades para incorporarse al mercado laboral y así poder acceder a una renta; es más, el individuo puede tener capacidad suficiente para convertirse en emprendedor o, incluso, gran empresario. En otras palabras, la educación y la formación permiten una mejor incorporación en la actividad económica.

Con independencia de esta inclusión económica, disponer de conocimientos permite a los individuos interrelacionarse mucho mejor con otras personas por lo que se puede evitar que se encuentren desplazados de la sociedad que les rodea, por tanto, la educación y formación también ayudan a la inclusión social; de hecho, los efectos favorables que se producen en este sentido con la educación y formación se han podido comprobar con los efectos favorables que han generado en muchos países la educación a mujeres, inmigrantes o personas con alguna discapacidad.

Por otro lado es evidente que determinados avances tecnológicos, especialmente relacionados con las Tecnologías de Información y Comunicación (TIC), han ampliado las posibilidades de facilitar el acceso a esta educación y formación a colectivos en situación de exclusión social o con riesgo de la misma, permitiendo que su inserción fuera más adecuada, e incluso, logrando que desapareciera el riesgo de pobreza existente.

Esta capacidad como mecanismo inclusivo, socialmente hablando, además de reducir la conflictividad social permite una estabilidad socioeconómica fundamental para cualquier evolución sostenible de una sociedad, lo que convierte a la educación y formación en un factor básico para la planificación económica a largo plazo. 


\subsection{Mayor conciencia respecto a la sostenibilidad medioambiental}

Cuando se analizan los recursos de un país uno de los factores a tener en cuenta es su población. No sólo hay que analizar cuántas personas hay o qué pirámide poblacional existe; hablar de población también es hablar de relaciones intergeneracionales y de calidad de vida.

Desde este punto de vista, gracias a la educación y la formación se pueden conseguir hábitos de vida más saludables que permitan eliminar algunas de las grandes lacras en los países menos avanzados (por ejemplo, hambrunas o algunas enfermedades) o que ponen en peligro la futura calidad de vida de los países más desarrollados (obesidad, dependencias, contaminación, etc.).

La educación y formación es una de las bases fundamentales para tomar conciencia de la situación medioambiental existente y de la necesidad de respetarla ahora y en un futuro (Figura 2). De hecho, el respeto al medioambiente y a los escasos recursos naturales existentes, empieza porque los individuos realmente se conciencien sobre estas cuestiones y eso se debe de iniciar a través de la educación básica (UNESCO, 2014, pp.11-12).

\section{Figura 2. Relación entre nivel de educación y Preocupación Medio Ambiente}

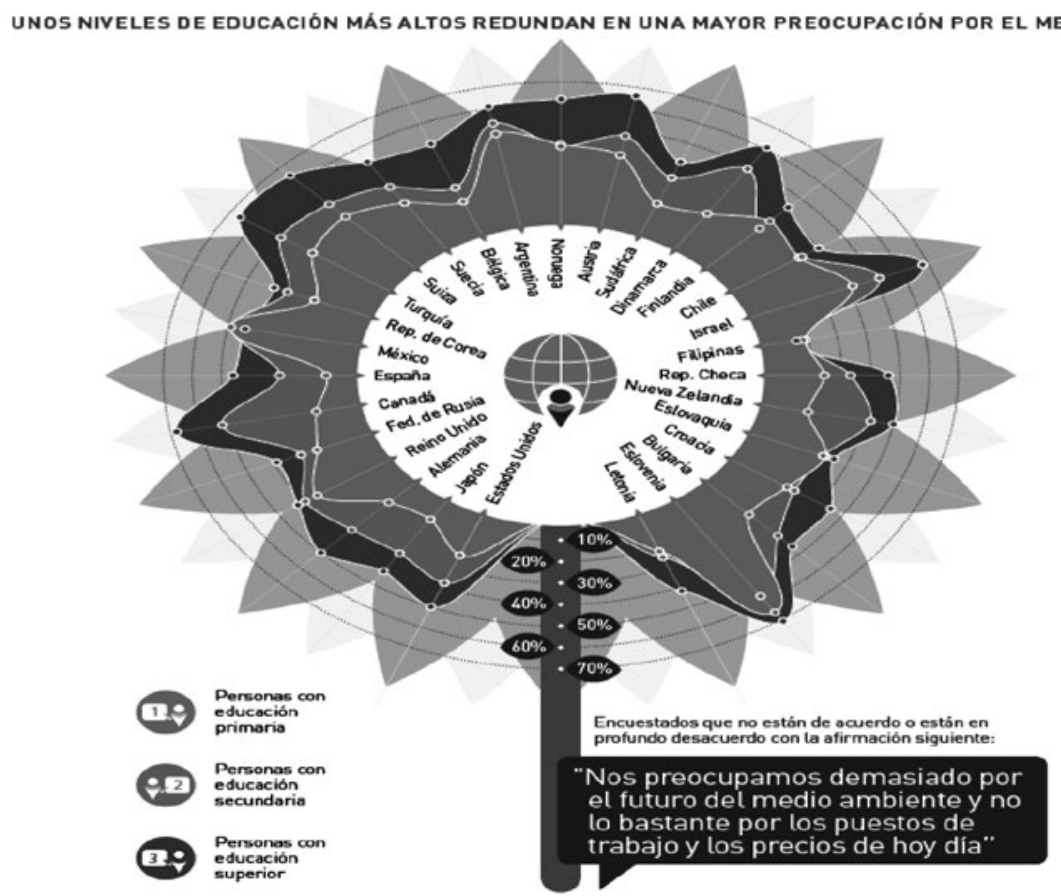

Fuente. UNESCO, 2014, p. 12. 


\subsection{Desarrollo económico sostenible}

Si la educación y la formación favorecen el crecimiento económico, la inserción social y la sostenibilidad medioambiental, parece lógico que se concluya que influyen de forma clara en el logro del Desarrollo Económico Sostenible que se desea alcanzar a nivel mundial.

Pese a la lógica que tiene el análisis, no se están logrando los objetivos establecidos y el planteamiento hasta ahora existente no parece demostrar que se haya podido avanzar mucho en esta dirección. En el Informe de Seguimiento de la Educación para Todos en el Mundo de la UNESCO (2014) se afirma claramente en su introducción:

"Durante más de medio siglo, la comunidad internacional de naciones ha reconocido que la educación es un derecho humano fundamental. En el año 2000, acordó los Objetivos de Desarrollo del Milenio, en los que se señala la educación como un medio indispensable para que las personas desarrollen su capacidad, y convirtió en una prioridad la terminación de un ciclo completo de enseñanza primaria.

Pese a la importancia fundamental de la educación en los tratados, los pactos y los acuerdos, la comunidad internacional todavía ha de reconocer todas las posibilidades de la educación como catalizador del desarrollo. Aunque, desde el año 2000, muchos gobiernos nacionales han aumentado su grado de compromiso con la educación y el apoyo que le prestan, entre los donantes y en muchos países ese compromiso continúa viéndose afectado por los cambios en las condiciones imperantes, sean estas financieras o de otra índole. La inversión en educación ha disminuido y va a la zaga de otros sectores del desarrollo".

\section{Grafico 1. Número de niños y adolescentes sin escolarizar a escala mundial, 2000-2013}

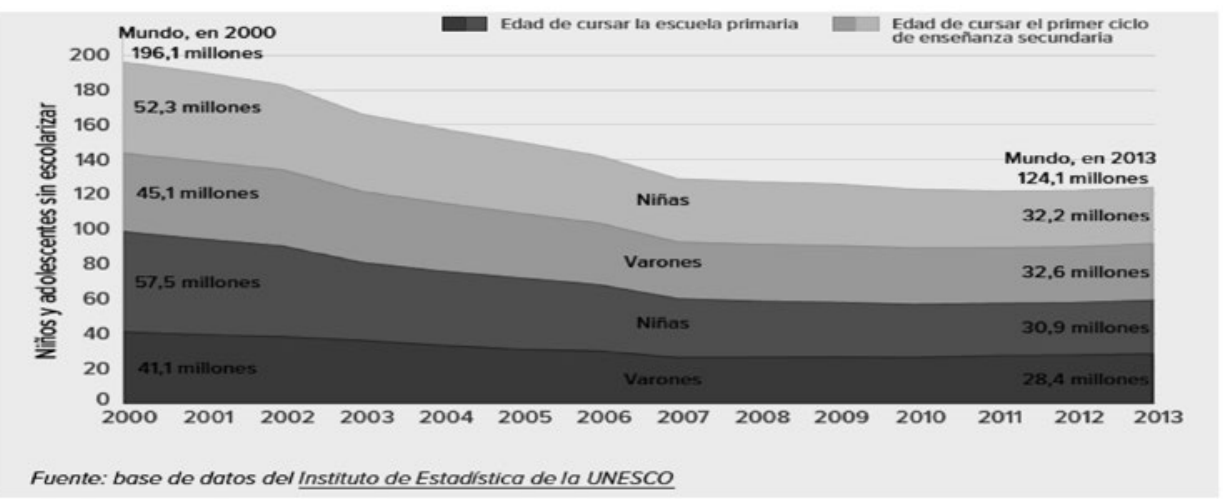

Fuente: UNESCO y UIS, 2015, p. 1. 
Según los datos del Informe de Seguimiento de UNESCO y su Instituto de Estadística (2015) todavía existían en el año 2013, a nivel mundial, 59 millones de niños sin acceso a educación primaria.

La UNESCO considera que factores como el incremento de niños en edad de escolarización en algunas áreas geográficas, los conflictos bélicos, la falta de fondos financieros y el aumento de niños en situación de exclusión social son factores que pueden explicar que no se estén logrando los objetivos establecidos, lo que exige un replanteamiento en las medidas que se están aplicando tanto a nivel nacional como internacional (Gráfico 1).

Si bien se suele considerar que en los países más avanzados la cobertura en educación básica es una cuestión solucionada, dicha visión es claramente un error ya que, incluso en esos países, existe un incumplimiento de este derecho (Gráfico 2).

\section{Gráfico 2. Contacto con la educación de los niños sin escolarizar en edad de cursar primaria \\ Por región, 2013}

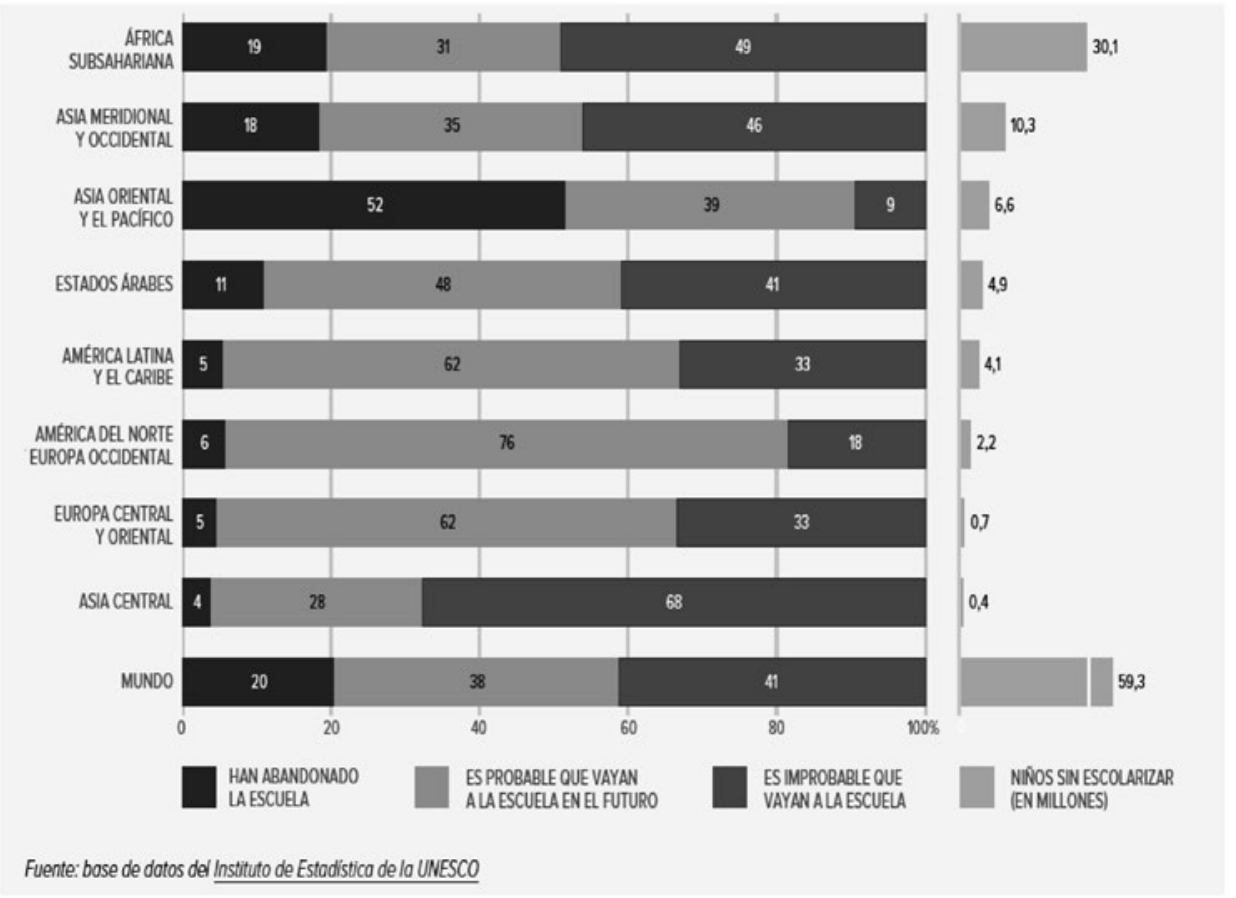

Fuente: UNESCO y UIS, 2015, p. 6.

Como se ha intentado demostrar, pese a la importancia de la educación y la formación como derecho y a las ventajas que aportan para lograr un adecuado de- 
sarrollo sostenible, respetuoso con el medio ambiente e inclusivo socialmente, a nivel mundial todavía queda mucho por hacer y las desigualdades internacionales siguen siendo muy importantes.

La disminución de las ayudas dedicadas a la educación por parte de algunos donantes en el periodo 2010-2013 y la mayor diversificación de las mismas entre educación primaria, secundaria y postsecundaria han hecho necesario volver a revindicar la importancia de la educación y la formación, especialmente de calidad, como uno de los Objetivos básicos para lograr un desarrollo sostenible no sólo en cada país sino también a nivel internacional.

El nuevo entorno socioeconómico existente a nivel internacional y la necesidad de replantearse las medidas que se toman en todos los ámbitos, incluido el económico, exige analizar si se están utilizando adecuadamente los recursos disponibles y si es posible mejorarlos. Teniendo en cuenta el poder que tiene la educación y la formación en la mejora de tres de los principales factores productivos de un país, es necesario reconsiderar el papel que tienen las mismas para el futuro de las naciones, no sólo desde el ámbito social sino también desde el económico, y analizar mejor cómo deben evolucionar tanto en cantidad como calidad.

\section{LA IMPORTANCIA DE LA EDUCACIÓN Y FORMACIÓN EN SITUACIONES DE CRISIS ECONÓMICAS}

Aunque ya se tenía presente la importancia de la educación y la formación en el desarrollo de los países, los efectos y avances que se han producido en los últimos años han puesto de manifiesto la necesidad de reconsiderar algunos factores cualitativos relacionados con las mismas. Es necesario prestar más atención a la calidad, adaptabilidad y diversidad de la educación y formación para lograr que realmente se convierta en un motor de Desarrollo Sostenible capaz de afrontar situaciones de desequilibrio económico o social.

Un buen ejemplo de este nuevo papel es la Resolución de la Asamblea General de la ONU el 25 de septiembre de 2015 (ONU, 2015, p.1), que recoge la Agenda 2030 donde se establecen los 17 nuevos objetivos que en quince años se pretenden alcanzar y, entre ellos, el "Objetivo 4 es Garantizar una educación inclusiva y equitativa de calidad y promover oportunidades de aprendizaje permanente para todos" (pp. 19-20). En este objetivo se destaca la importancia de la educación con la cual se desea poner las bases para que, en el 2030, las jóvenes generaciones actuales puedan continuar con el proceso que ahora se ha iniciado:

"25. Nos comprometemos a proporcionar una educación de calidad, inclusiva e igualitaria a todos los niveles: enseñanza preescolar, primaria, secundaria y terciaria y formación técnica y profesional. Todas las perso- 
nas, sea cual sea su sexo, raza u origen étnico, incluidas las personas con discapacidad, los migrantes, los pueblos indígenas, los niños y los jóvenes, especialmente si se encuentran en situaciones de vulnerabilidad, deben tener acceso a posibilidades de aprendizaje permanente que las ayuden a adquirir los conocimientos y aptitudes necesarios para aprovechar las oportunidades que se les presenten y participar plenamente en la sociedad. Nos esforzaremos por brindar a los niños y los jóvenes un entorno propicio para la plena realización de sus derechos y capacidades, ayudando a nuestros países a sacar partido al dividendo demográfico, incluso mediante la seguridad en las escuelas y la cohesión de las comunidades y las familias." (p. 8) "27. Procuraremos sentar unas bases económicas sólidas en todos nuestros países. El crecimiento económico sostenido, inclusivo y sostenible es esencial para lograr la prosperidad, lo que solo será posible si se comparte la riqueza y se combate la desigualdad de los ingresos. Trabajaremos para construir economías dinámicas, sostenibles, innovadoras y centradas en las personas, promoviendo en particular el empleo de los jóvenes y el empoderamiento económico de las mujeres, así como el trabajo decente para todos. Erradicaremos el trabajo forzoso y la trata de personas y pondremos fin al trabajo infantil en todas sus formas. Todos los países saldrán ganando si disponen de una fuerza de trabajo sana, con buena formación y con los conocimientos y aptitudes necesarios para realizar un trabajo productivo y gratificante y participar plenamente en la sociedad. (...)” (p. 9).

"51. Lo que hoy anunciamos -una Agenda para la acción mundial durante los próximos 15 años- es una carta para las personas y el planeta en el siglo XXI. Los niños y los jóvenes de ambos sexos son agentes fundamentales del cambio y encontrarán en los nuevos Objetivos una plataforma para encauzar su infinita capacidad de activismo hacia la creación de un mundo mejor." (p. 14).

Es indudable que a nivel internacional la educación y la formación están consideradas como piezas claves para crear economías sostenibles, inclusivas y dinámicas, capaces de crear individuos y sociedades que puedan afrontar los cambios socioeconómicos que se puedan presentar, a nivel nacional e internacional, tanto por cuestiones estructurales como de tipo coyuntural.

Aunque esto significa un avance, no se debe de olvidar que es un objetivo para 2030 y la experiencia ha demostrado que el proceso es lento y que todavía queda mucho camino por recorrer en cuanto al papel que se adjudica a la educación y la formación en los distintos países y, mucho más, en la disminución de las diferencias que existen a nivel internacional con respecto a unas de sus principales aportaciones directas: la investigación, el desarrollo y la innovación (I+D+i).

Pese a todo lo que se ha hablado y escrito sobre la importancia de la educación y la formación para el ámbito económico, hay una cuestión que siempre parece 
olvidarse: ambas permiten amortiguar las crisis económicas y aumentan el crecimiento en situaciones de expansión.

En este sentido es fundamental tomar conciencia del papel que juegan para afrontar y superar situaciones de crisis tanto a nivel social como económico; por tanto, conviene analizar en qué medida las autoridades son conscientes de la importancia que tiene una educación de calidad para evitar parte de los efectos negativos de las crisis.

\section{LA POLÍTICA DE EDUCACIÓN Y FORMACIÓN Y LA POLÍTICA DE I+D+i EN LA UE}

Una vez expuesto el análisis internacional de la importancia que tiene la Política de educación y formación, tanto desde el punto de vista social como económico, y de su potencial como amortiguador ante situaciones de crisis económicas se considera importante realizar una referencia específica al caso de la Unión Europea ya que, de esa forma, se podrá valorar mejor en qué medida se tiene conciencia del verdadero valor de la educación y formación para lograr una sostenibilidad en el desarrollo económico.

El papel de la educación y la formación en el ámbito de lo que hoy se conoce como Unión Europea ha estado durante muchos años asociado a su reconocimiento como Derecho Universal (Carta Social Europea, 1961 revisada en 19966\% Pacto Internacional de Derecho Económicos, Sociales y Culturales, 1966; Carta de Derechos Fundamentales de la Unión Europea, 2010); sin embargo, es a partir de la Declaración de Bolonia ${ }^{8}$ realizada por los Ministros de Educación europeos en junio de 1999 cuando se inicia el llamado Proceso de Bolonia, el cual queda asociado a las Conclusiones de la Presidencia del Consejo Europeo de Lisboa de marzo del $2000^{9}$ en las que la educación, la formación y el I+D+i empiezan a adquirir un papel importante dentro de la Unión Europea.

En la nueva estrategia que se estableció en esta reunión del Consejo, quedó claro la necesidad de desarrollar una economía europea capaz de adaptarse al nuevo entorno internacional existente y para ello se consideró conveniente potenciar una nueva economía basada en el conocimiento, capaz de eliminar algunas de las debilidades que se estaban observando en ese momento en los mercados laborales europeos (cifras de paro estructural importantes, claras desigualdades regionales y difícil incorporación al mercado de mujeres y trabajadores de mayor edad).

\footnotetext{
${ }^{6}$ Muy centrada en el aspecto de formación para empleabilidad. Véanse art. 1.4, 9, 10 y 15.

${ }^{7}$ Entrada en vigor el 3 de enero de 1976. Artículos 13 y 14. Véase http://www.derechoshumanos.net/ derechos/index.htm\#educacion.

${ }^{8}$ Esta declaración inició el Proceso de Bolonia, revisable cada tres años, y que dio lugar en la Declaración Budapest-Viena de 20120 al Espacio Europeo de Educación Superior (EEES). Para más información http://eur-lex.europa.eu/legal-content/ES/TXT/?uri=URISERV: c11088.

${ }^{9}$ http://www.minhap.gob.es/Documentacion/Publico/SGPEDC/Estrategia\%20de\%20Lisboa.pdf
} 
La Estrategia de Lisboa, del año 2000, dejó claro que se necesitaba una actuación global que generara una sociedad basada en el conocimiento, en donde tuviese un importante papel la creación de capital humano a través de la educación y la formación y, en la cual, la I+D complementadas con el apoyo de medidas de fomento de innovación pudiera lograr que la UE se convirtiera en más dinámica, capaz de crecer económicamente de forma más sostenible, que generara más y mejores empleos y pudiera lograr mayor cohesión social (Parlamento Europeo, 2000).

En la Unión Europea (UE) los aspectos fundamentales sobre educación, formación e I+D+i ya se establecieron con claridad en la Estrategia de Lisboa y se pusieron en marcha en el Consejo Europeo de Barcelona, celebrado en marzo de 2002, donde se aprobó el Programa Educación y Formación 2010, con el objetivo de incrementar la cooperación en el ámbito de la educación y la formación en el ámbito de la UE.

Desde ese momento, se han realizado importantes avances entre los que se pueden destacar dos:

a) Las Conclusiones del Consejo, de 12 de mayo de 2009, sobre un Marco estratégico para la cooperación europea en el ámbito de la educación y la formación (ET 2020) (Ministerio Educación, Cultura y Deporte, 2013), se insiste en seguir desarrollando los sistemas de educación y formación de los Estados de la UE para que todos los ciudadanos puedan aprovechar al máximo el potencial que poseen y así se pueda lograr mayor prosperidad económica y nivel de empleo en el ámbito de la Unión. En este momento se establecieron cuatro nuevos objetivos: hacer realidad el aprendizaje a lo largo de la vida y la movilidad ${ }^{10}$; mejorar la calidad y eficiencia de la educación y la formación ${ }^{11}$; promover la equidad, la cohesión social y la ciudadanía activa ${ }^{12}$; afianzar la creatividad y la innovación, incluyendo el espíritu emprendedor, en todos los niveles de educación y formación ${ }^{13}$.

b) Reglamento (UE) no 1291/2013 del Parlamento europeo y del Consejo, de 11 de diciembre de 2013, por el que se establece Horizonte 2020, Programa

\footnotetext{
${ }^{10}$ En este objetivo 1 se establece que; al menos un $15 \%$ de los adultos con edades comprendidas entre 25 y 64 años debería participar en aprendizaje permanente y, por lo menos, el 20\% de los graduados en Educación Terciaria y un 6\% de jóvenes entre 18 y 34 años con cualificación de formación profesional inicial deberían pasar un periodo de estudio o formación en el extranjero.

${ }^{11}$ En el objetivo 2 se desea que; el porcentaje de alumnos de 15 años con bajo rendimiento en competencias básicas en Lectura, Matemáticas y Ciencias debería ser inferior al 15\%; punto de referencia sobre lenguas extranjeras; el porcentaje de graduados en Educación Secundaria segunda etapa, postsecundaria no terciaria o Terciaria (CINE 3-6) entre 20 y 34 años que se han graduado entre 1 y 3 años anteriores al año de referencia y que están empleados, debería ser por lo menos del $82 \%$.

${ }^{12}$ En el objetivo 3 se indica que al menos el 95\% de los niños/as entre cuatro años de edad y la edad de comienzo de la Educación Primaria deberían participar en Educación Infantil y que, el porcentaje de los que abandonan de forma temprana la educación y la formación debería ser inferior al 10\%.

${ }^{13}$ Por último, el objetivo 4 establece que el porcentaje de personas de edades comprendidas entre $30 \mathrm{y}$ 34 años que hayan completado con éxito el nivel de Educación Terciaria debería ser por lo menos del $40 \%$.
} 
Marco de Investigación e Innovación (2014-2020) (Comisión Europea, 2013), en donde se reconoce la necesidad de establecer un adecuado Espacio Europeo de Investigación (EEI) para poder alcanzar los objetivos establecidos en la estrategia Europa 2020. En este Programa Marco se expone que no es suficiente con crear conocimiento, es fundamental que el mismo circule y que las investigaciones y desarrollos realizados se transformen en innovación real ya que esto es lo que permitirá que la economía europea sea más competitiva.

Todas estas medidas de la Unión Europea, y de sus países miembros, se enmarcan dentro de los cambios promovidos por la estrategia Europa 2020 que exigen actuaciones de política económica que no se fijen sólo en el corto plazo; es más, se consideran muy importante vigilar cómo van evolucionando las medidas aplicadas y realizar los cambios que sean necesarios para que éstas resulten realmente adecuadas. Este nuevo enfoque es el que se está utilizando en la Unión con los cambios que se desean realizar en la educación, la formación, la investigación, el desarrollo y la innovación para convertirlos en un sólido pilar que permita conseguir un adecuado desarrollo económico sostenible e inteligente para el año 2020.

Si ya resulta difícil, dados los diversos agentes implicados, combinar la visión de la educación y la formación como derecho fundamental con una visión en la que se tenga en cuenta la importancia socioeconómica que tienen las mismas; convertir las políticas de educación y formación y la de investigación, desarrollo e innovación en pilares fundamentales para conseguir los principales objetivos económicos de la Unión Europea implica lograr un cambio de mentalidad, tanto en las autoridades como en la propia sociedad, que permita colocar estas políticas, típicamente sociales, en el lugar que les corresponde desde el punto de vista económico.

Las medidas aplicadas en los ámbitos antes indicados no son sólo para cubrir un derecho, sino que son fundamentales para mantener la propia esencia de lo que desea conseguir la Unión Europea. Sin una adecuada educación y formación no será posible interrelacionar los distintos pueblos de la Unión ni crear una verdadera ciudadanía europea. No se podrá desarrollar capital humano de calidad ni se creará capital social ni tecnológico, lo que dificultará lograr una sociedad más desarrollada, más inclusiva y más sensible con los problemas del medio ambiente. Por último, sin una adecuada investigación, desarrollo e innovación no se avanzará en el conocimiento, ni se alcanzarán mayores niveles de competitividad lo que puede perjudicar claramente el posicionamiento de la Unión a nivel internacional.

Ante esta situación, resulta insuficiente limitarse a establecer normas o fijar ciertas medidas para alcanzar algunos objetivos parciales, lo fundamental es que las autoridades tomen más conciencia de la interrelación existente entre la educación y la formación y la economía. Ambas son Ciencias Sociales y deben de estar correctamente vinculadas ya que no vale con afirmar que la educación y la formación favorecen alcanzar algunos de los objetivos fundamentales establecidos en el ámbi- 
to económico; en realidad, la evolución de la economía de un país y su capacidad para afrontar mejor situaciones de desequilibrio dependen de cómo se desarrolle y evolucione la educación y la formación en el mismo y de cómo se aprovechen todas las oportunidades que éstas generan. Es más, una inadecuada evolución en la educación y la formación o en uno de sus efectos más directos, la investigación y desarrollo, pueden generar consecuencias negativas en el ámbito económico (falta de individuos cualificados o con conocimientos obsoletos, atraso tecnológico, etc.).

Aunque se haya avanzado mucho en el papel que tienen la educación y la formación, todavía es necesario que autoridades europeas tomen conciencia de la necesidad de afrontar dos aspectos fundamentales para que se acerquen la política de educación y formación a las verdaderas necesidades de los Estados de la Unión, en concreto, se considera esencial:

1. Aumentar la calidad en la educación y la formación.

2. Eliminar los desajustes entre la educación y formación y la realidad existente.

\subsection{Aumentar la calidad en la educación y la formación}

Resulta claro que la educación tiene importantes externalidades positivas y que puede generar efectos redistributivos a nivel socioeconómico; de hecho, se la podría considerar como una necesidad preferente. Si se tienen en cuenta estas cuestiones, los gastos que las administraciones públicas destinen a la educación tienen importantes consecuencias estabilizadoras que explican y justifican la necesidad de su dotación como gasto público esencial en cualquier nación.

Si se observa la evolución del Gasto Público en Educación, parece que las autoridades han tomado conciencia de la necesidad de invertir en educación ya que, en valor absoluto, el gasto en educación ha aumentado en la mayoría de los países europeos durante el período 2006-2011. No obstante, si se compara este gasto en relación con el gasto público total realizado se puede observar que, según el informe de la OCDE de 2014 (p. 47), en los últimos años el porcentaje de Gasto Público Total en Educación respecto al Gasto Público Total no es tan alto como parece; de hecho, según se muestra en el Cuadro 1 y Gráfico 3, en algunos países el esfuerzo que se está realizando para fomentar la educación, en general, y la de calidad, en particular, es insuficiente.

Ante esta situación, se están produciendo diversas aportaciones, como la de A. de la Fuente y J. F. Jimeno (2011), que ponen de manifiesto la necesidad de que las autoridades incluyan nuevas variables a la hora de decidir sus inversiones en educación valorando, por ejemplo, que la rentabilidad privada y pública de la inversión en la misma puede ser positiva tanto para el individuo como para el sector público y la sociedad en su conjunto. La inclusión de estos beneficios complementarios debería incentivar la inversión en educación como necesidad preferente, separándola de la relación existente con la situación económica que se da en el país. 


\section{Cuadro 1. Gasto Público total en educación en relación con el PIB (\%)}

\begin{tabular}{|c|c|c|}
\hline & 2006 & 2011 \\
\hline Unión Europea (28 países) ${ }^{(1)}$ & 4,91 & 5,25 \\
\hline Alemania & 4,43 & 4,98 \\
\hline Austria & 5,40 & 5,80 \\
\hline Bélgica & $5,98^{(2)}$ & $6,55^{(2)}$ \\
\hline Bulgaria & 4,04 & 3,82 \\
\hline Chipre & $7,02^{(2)}$ & $7,87^{(2)}$ \\
\hline Croacia & $4,04^{(2)}$ & $4,21^{(2)}$ \\
\hline Dinamarca & $7,97^{(2)}$ & $8,75^{(2)}$ \\
\hline Eslovenia & 5,72 & 5,68 \\
\hline España & 4,26 & 4,82 \\
\hline Estonia & 4,70 & 5,16 \\
\hline Finlandia & 6,18 & 6,76 \\
\hline Francia & 5,61 & 5,68 \\
\hline Grecia & - & - \\
\hline Hungría & 5,44 & 4,71 \\
\hline Irlanda & 4,73 & 6,15 \\
\hline Italia & 4,67 & 4,29 \\
\hline Letonia & 5,13 & 4,96 \\
\hline Lituania & 4,82 & 5,17 \\
\hline Luxemburgo & $3,41^{(2)}$ & - \\
\hline Malta & 6,45 & 7,96 \\
\hline Países Bajos & 5,50 & 5,93 \\
\hline Polonia & $5,25^{(2)}$ & 4,94 \\
\hline Portugal & $5,07^{(2)}$ & $5,27^{(2)}$ \\
\hline R. Checa & 4,42 & 4,51 \\
\hline R. Eslovaca & $3,80^{(2)}$ & $4,06^{(2)}$ \\
\hline Reino Unido & $5,38^{(2)}$ & $5,98^{(2)}$ \\
\hline Rumanía & $-{ }^{(3)}$ & 3,07 \\
\hline Suecia & 6,75 & 6,82 \\
\hline \multicolumn{3}{|l|}{ Otros Países Europeos } \\
\hline Islandia & 7,55 & $7,36^{(2)}$ \\
\hline Noruega & 6,49 & 6,66 \\
\hline Suiza & 5,28 & 5,28 \\
\hline Turquía & 2,86 & 4,07 \\
\hline \multicolumn{3}{|l|}{ Otros países } \\
\hline Estados Unidos & $5,24^{(2)}$ & $5,13^{(2)}$ \\
\hline Japón & $3,46^{(2)}$ & 3,78 \\
\hline
\end{tabular}

(1) Estimación de EUROSTAT.

(2) La definición del indicador difiere para estos datos.

(3) Datos con problemas de fiabilidad.

Fuente: Ministerio de Educación Cultura y Deportes, septiembre 2015. http//: www.mec.gob.es (fecha de consulta 1 de octubre 2015). 
Además de considerar la importancia que tiene invertir en educación, resulta fundamental tener en cuenta la calidad de la misma. Para conseguir obtener buenos resultados a nivel económico y social es necesario que lo que se invierta en educación permita adquirir a los individuos mayores cualificaciones y habilidades que les den; mejor acceso al mercado laboral (ya sea como trabajadores por cuenta ajena o propia); mayores posibilidades para obtener unos salarios más altos, que puedan permitir más consumo, ahorro y recaudación impositiva y; más iniciativa emprendedora, tanto en el ámbito teórico como práctico, ya que eso es lo que permitirá crear investigación y desarrollo y hacer más competitiva la nación, lo que aumentará las posibilidades de alcanzar sociedades más equitativas, inclusivas y sostenibles a largo plazo.

\section{Gráfico 3. Gasto Público Total en Educación como porcentaje del Gasto Público Total Por niveles educativos de formación (2011)}

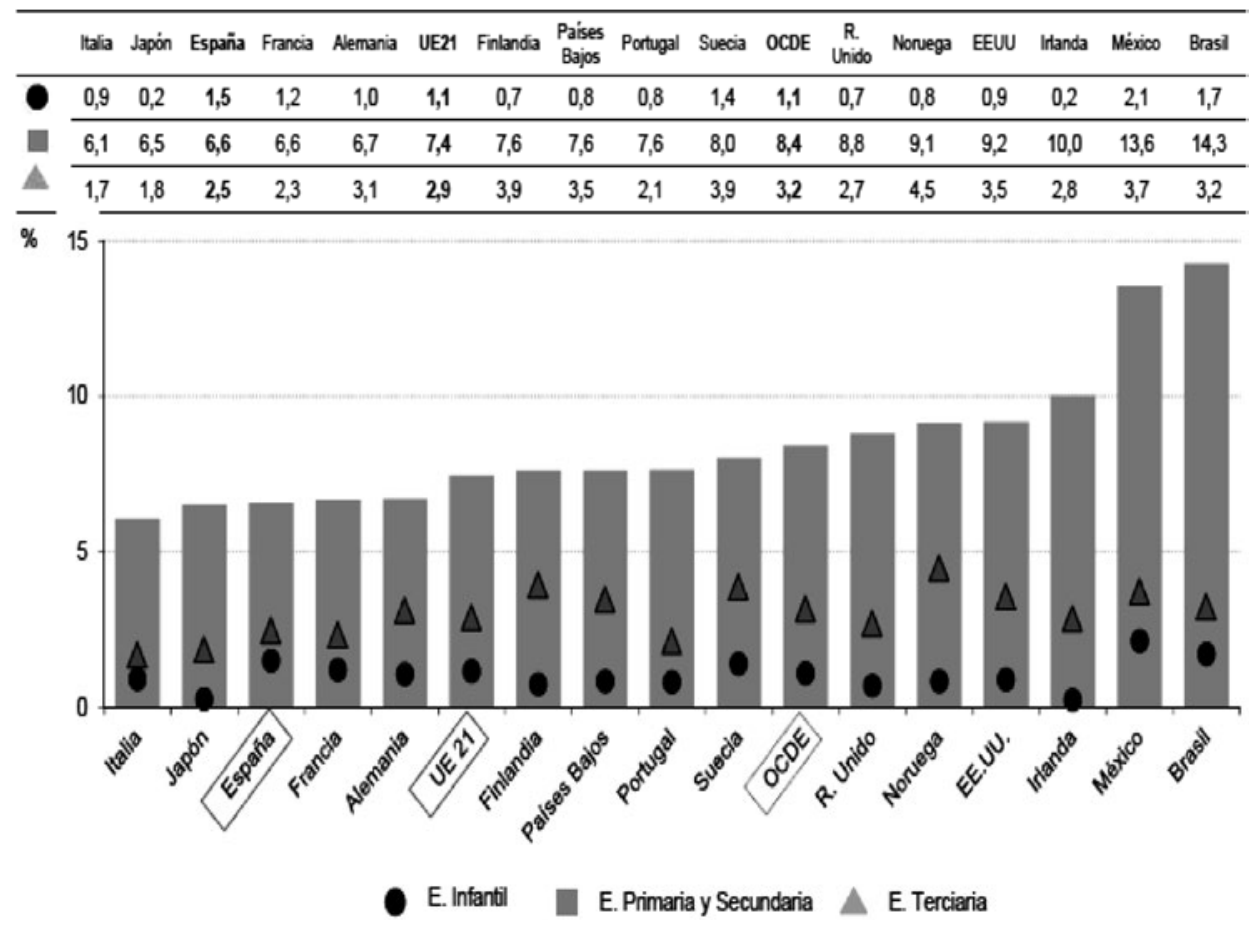

Nota: Los países están ordenados de manor a mayor gasto público en instituciones educativas como porcentaje del gasto público total en Educación Primaria, secundaria y postsecundaria no Terciaria.

Fuente: Ministerio de Educación, Cultura y Deporte, 2014, p. 47. 
Para lograr una educación y formación de calidad es necesario disponer, como mínimo, de dos factores fundamentales: suficientes docentes preparados y motivados y unas infraestructuras adecuadas que faciliten la transmisión y generación del conocimiento.

1. Se necesitan docentes preparados para cubrir las diversas necesidades formativas que se puedan necesitar dentro del país. A los docentes conviene proporcionarles una formación continua adaptada a sus necesidades, a los cambios que se produzcan en las materias que van a impartir ${ }^{14} \mathrm{y}$, por último, a las innovaciones tecnológicas y pedagógicas que puedan mejorar su actividad. Por otro lado, es fundamental que los docentes, como trasmisores de conocimientos y del saber hacer, se sientan adecuadamente valorados. Para que se pueda alcanzar una formación eficaz, los docentes deben de ser informados de los resultados de las evaluaciones que los alumnos hayan podido realizar de ellos, ya que solo de esta forma se podrán realizar los ajustes que sean necesarios y mejorar la relación alumnos-profesor (OCDE, 2012, pp. 2-3). De hecho, si los docentes ven estas evaluaciones como algo positivo para su actividad se puede lograr una mejora tanto en contenidos como en la transmisión de conocimientos; sin embargo, si las mismas solo se utilizan como un mecanismo de control, los docentes pueden olvidar su objetivo fundamental, mejorar la calidad del aprendizaje, y derivar hacia una enseñanza que únicamente busque cumplir con el control aunque sea a costa de la calidad de la educación. Por último, como cualquier otro trabajador, los docentes deben tener posibilidades de promoción y una estabilidad laboral que les incentive para mejorar en contenidos y en innovación docente (Ministerio de Educación, Cultura y Deporte, 2014, p. 54-63; OCDE, 2013) lo que, evidentemente, beneficia a la calidad de la enseñanza.

Pese a que todo lo expuesto parece obvio y en todos los foros educativos se insiste en ello, la realidad demuestra que no está claro si las autoridades son conscientes de estas cuestiones ya que en muchos países cuando se inició la crisis de 2007 y, especialmente, desde el 2009 las condiciones laborales de los docentes se han visto negativamente afectadas, lo que claramente puede afectar a la calidad de la enseñanza y provocar unos efectos inadecuados en el futuro capital humano de las naciones (OCDE, 2013, pp. 2-3).

\footnotetext{
${ }^{14}$ En lo últimos años, en algunos países como por ejemplo en España, se ha producido cierta controversia con respecto a la calidad con la que se dan las materias y la necesidad de preparar a los alumnos para un mundo globalizado en el que resulta fundamental disponer, como mínimo, de un segundo idioma. Si bien se considera fundamental fomentar el bilingüismo, el problema se plantea en cómo incorporarlo y sobre qué materias aplicarlo ya que puede darse el caso de que la transmisión del conocimiento de una materia pueda verse negativamente afectado por un manejo insuficiente del segundo idioma, tanto por parte del alumno como por el docente, o lo que es más grave, que prime el conocimiento del idioma sobre el de la materia lo que disminuye claramente la calidad de la enseñanza recibida (puede verse Padilla, 1999; Anghel, Cabrales y. Carro, 2013)
} 
2. Disponer de las infraestructuras adecuadas en cada una de las etapas educativas. Una educación y formación de calidad necesita un entorno adecuado en donde tanto los alumnos como los profesores puedan realizar sus actividades de forma correcta. En este sentido, se puede destacar la necesidad de una adecuada dotación dentro de los correspondientes edificios, laboratorios, espacios para seminarios o actividades complementarias, lugares para el estudio y adecuada dotación documental, un mínimo de posibilidades de aprovechar las ventajas ofrecidas por las tecnologías de la información y comunicación, unas normas de convivencia que favorezcan las condiciones de la formación y el aprendizaje de calidad, tanto en el ámbito teórico como práctico, etc.

El principal problema que se puede plantear para las autoridades al afrontar esta cuestión es la distribución de los escasos fondos existentes entre todas estas necesidades; de hecho, en algunos de los países de la Unión Europea existe cierta controversia sobre si los fondos públicos deben dedicarse a mejorar las infraestructuras de la enseñanza pública o a favorecer a centros concertados. En realidad, es normal que los fondos se dividan entre ambos tipos de instituciones porque, en ocasiones, es mejor utilizar un centro educativo ya existente que crear una nueva institución pública; sin embargo, es muy importante establecer un adecuado control sobre cómo se están utilizando los fondos públicos, determinar claramente la autonomía que se da a los centros concertados y, mantener un sistema que permita garantizar que esos fondos van destinados a una educación de calidad accesible a todos los individuos de igual forma que si se hubiera ofrecido el servicio de forma pública (OCDE, 2014).

En definitiva, se puede afirmar que la calidad de la educación y la formación es un tema de interés para la Unión Europea desde hace tiempo; sin embargo, la situación de crisis que ha existido en los últimos años ha hecho que en la práctica, pese a las recomendaciones de especialistas y de organismos internacionales, no se haya avanzado todo lo deseable en su mejora. Este comportamiento impide disponer de una población con suficientes conocimientos y habilidades de calidad, más flexible y capacitada para afrontar mejor algunos de los importantes problemas socioeconómicos que se suelen dar en momentos de crisis económicas (por ejemplo, reducción de actividades productivas o paro).

\subsection{Eliminar los desajustes entre la educación y la formación y la realidad existente}

La experiencia existente en el ámbito de la Unión Europeo ha puesto de manifiesto la existencia de ciertos desajustes entre la educación y formación desarrollada y las necesidades reales existentes, lo que conlleva unas consecuencias 
sociales y económicas que hay que evitar, entre ellas: el desempleo, siendo especialmente problemática la tasa de paro juvenil; las desigualdades territoriales y personales de renta o la falta de competitividad en determinadas producciones.

Aunque a nivel europeo ya se han iniciado algunas iniciativas y programas para solucionar estos problemas, los desajustes existentes son todavía muy importantes lo que hace necesario fortalecer lo establecido, e incluso, buscar nuevas medidas. En este sentido es importante: coordinar mejor las distintas etapas educativas; adaptar la educación y la formación a las necesidades reales del mercado laboral; incrementar los niveles de formación continua; equilibrar el nivel de la investigación, el desarrollo y la innovación en la Unión.

3.2.1. Coordinar las medidas existentes a nivel de la educación superior con las aplicadas en las etapas previas y reducir el abandono escolar

Además de coordinar las políticas educativas a nivel superior (Espacio Europeo de Educación Superior) es necesario que se colabore más en educación secundaria y primaria ya que éstas son la base de lo que luego pueda suceder a nivel de educación superior universitaria y no universitaria.

Los niveles de abandono escolar y los problemas que se están produciendo en las primeras fases de la educación (Cuadro 2) ponen en peligro la adecuada evolución futura de la economía europea ya que representan una perdida en el capital humano que puede afectar a la futura competitividad de la Unión y, lo más peligroso, aumenta las posibilidades de la aparición de situaciones de exclusión social.

Aunque se haya establecido un período de educación obligatoria para poder ejercer el derecho que tiene todo individuo a la educación, en algunos países de la Unión, el abandono escolar existente es demasiado alto, lo que pone de manifiesto que algo está fallando.

Este abandono escolar incentiva que se mantenga un alto porcentaje de personas con un nivel de cualificación baja, lo que dificulta su incorporación al mercado laboral (Gráfico 4) y, en consecuencia, agudiza el problema de desempleo existente en la Unión. Además, está demostrado que estas personas con bajas cualificaciones tienen limitas las posibilidades de acceso a determinados puestos de trabajo, por lo que su nivel salarial es inferior al que pueden alcanzar los trabajadores más cualificados (Gráfico 4) lo que puede afectar negativamente a la evolución de la demanda de consumo y el nivel de ahorro a medio y largo plazo.

Teniendo en cuenta que parte de las personas que abandonan los estudios tendrán dificultades para incorporarse al mercado laboral y, si lo consiguen, tienen pocas posibilidades de alcanzar unos niveles salariales altos se puede afirmar que, si no se aborda adecuadamente el abandono escolar, se corre el peligro de no poder disminuir el nivel de población en riesgo de exclusión social y de no lograr el objetivo europeo de crear una economía inclusiva en la Unión Europea (Gráfico 5). 
Cuadro 2. Abandono educativo temprano (1) (2). Porcentaje de población entre 18 y 24 años que no ha completado la Educación Secundaria $2^{\text {a }}$ etapa y no sigue ningún tipo de estudio-formación

\begin{tabular}{|c|c|c|c|c|c|c|c|c|c|}
\hline & \multicolumn{3}{|c|}{ TOTAL } & \multicolumn{3}{|c|}{ HOMBRES } & \multicolumn{3}{|c|}{ MUJERES } \\
\hline & 2003 & 2008 & 2013 & 2003 & 2008 & 2013 & 2003 & 2008 & 2013 \\
\hline $\begin{array}{l}\text { Unión Europea } \\
\text { (28 países) }\end{array}$ & $16,4^{(4)}$ & 14,7 & 12,0 & $18,5^{(4)}$ & 16,7 & 13,6 & $14,3^{(4)}$ & 12,7 & 10,2 \\
\hline Alemania & $12,8^{(3)}$ & 11,8 & 9,9 & $12,9^{(3)}$ & 12,4 & 10,4 & $12,8^{(3)}$ & 11,2 & 9,3 \\
\hline Austria & $9,0^{(4)}$ & 10,1 & 7,3 & $8,3^{(4)}$ & 10,4 & 7,7 & $9,8^{(4)}$ & 9,8 & 7,0 \\
\hline Bélgica & 14,3 & 12,0 & 11,0 & 16,9 & 13,4 & 13,2 & 11,6 & 10,6 & 8,7 \\
\hline Bulgaria & 21,9 & 14,8 & 12,5 & 22,5 & 14,1 & 12,3 & 21,3 & 15,5 & 12,7 \\
\hline Croacia & $17,3^{(4)}$ & 13,7 & 9,1 & $24,1^{(4)}$ & 19,0 & 14,8 & $11,8^{(4)}$ & 9,5 & 4,2 \\
\hline Chipre & 7,9 & 3,7 & 3,7 & $9,2^{(6)}$ & $4,1^{(6)}$ & 4,7 & $6,4^{(6)}$ & $3,3^{(6)}$ & $2,6^{(6)}$ \\
\hline Dinamarca & $10,4^{(4)}$ & 12,5 & 8,0 & $10,7^{(4)}$ & 15,0 & 9,9 & $10,0^{(4)}$ & 10,0 & 6,2 \\
\hline Eslovenia & $4,6^{(4)}$ & 5,1 & 3,9 & $6,6^{(4)}$ & 7,2 & 5,0 & $2,4^{(6)}$ & $2,6^{(6)}$ & $2,6^{(6)}$ \\
\hline España & 31,7 & 31,7 & 23,6 & 38,4 & 38,0 & 27,2 & 24,8 & 25,1 & 19,8 \\
\hline Estonia & 13,7 & 14,0 & 9,7 & 18,3 & 19,8 & 13,6 & 8,8 & 8,3 & 5,8 \\
\hline Finlandia & $10,1^{(4)}$ & 9,8 & 9,3 & $12,0^{(4)}$ & 12,1 & 10,4 & $8,2^{(4)}$ & 7,7 & 8,3 \\
\hline Francia & $12,4^{(4)}$ & 11,5 & $9,7^{(4)}$ & $14,0^{(4)}$ & 13,5 & $10,7^{(6)}$ & $10,8^{(4)}$ & 9,5 & $8,8^{(4)}$ \\
\hline Grecia & $16,0^{(4)}$ & 14,8 & 10,1 & $20,0^{(4)}$ & 18,5 & 12,7 & $11,9^{(4)}$ & 10,9 & 7,6 \\
\hline Hungría & $12,0^{(4)}$ & 11,7 & 11,8 & $12,7^{(4)}$ & 12,5 & 12,5 & $11,3^{(4)}$ & 10,9 & 11,1 \\
\hline Irlanda & $13,1^{(4)}$ & 11,3 & 8,4 & $16,2^{(4)}$ & 14,5 & 9,8 & $9,8^{(4)}$ & 8,0 & 6,9 \\
\hline Italia & 23,0 & 19,7 & 17,0 & 26,5 & 22,6 & 20,2 & 19,6 & 16,7 & 13,7 \\
\hline Letonia & 18,0 & 15,5 & 9,8 & 22,6 & 20,0 & 13,6 & 13,4 & 10,8 & 5,8 \\
\hline Lituania & 11,4 & 7,5 & 6,3 & 13,6 & $10,2^{(6)}$ & 7,8 & $9,1^{(6)}$ & $4,7^{(6)}$ & $4,7^{(6)}$ \\
\hline Luxemburgo & $12,3^{(4)}$ & 13,4 & 6,1 & $14,3^{(4)}$ & 15,8 & 8,4 & $10,2^{(4)}$ & 10,9 & $3,7^{(6)}$ \\
\hline Malta & $49,9^{(5)}$ & 27,2 & 20,8 & $51,7^{(5)}$ & 31,1 & 23,2 & $48,0^{(5)}$ & 23,2 & 18,4 \\
\hline Países Bajos & $14,3^{(4)}$ & 11,4 & 9,2 & $15,6^{(4)}$ & 14,0 & 10,9 & $12,9^{(4)}$ & 8,8 & 7,4 \\
\hline Polonia & 6,0 & 5,0 & 5,6 & 7,6 & 6,1 & 7,9 & 4,4 & 3,9 & 3,2 \\
\hline Portugal & 41,2 & 35,4 & 19,2 & 48,7 & 41,9 & 23,6 & 33,6 & 28,6 & 14,5 \\
\hline R. Checa & $6,5^{(4)}$ & 5,6 & 5,4 & $5,9^{(4)}$ & 5,8 & 5,4 & $7,0^{(4)}$ & 5,4 & 5,5 \\
\hline R. Eslovaca & $5,3^{(4)}$ & 6,0 & 6,4 & $5,7^{(4)}$ & 7,1 & 6,7 & $4,8^{(4)}$ & 4,9 & 6,1 \\
\hline Reino Unido & $12,1^{(4)}$ & 17,0 & 12,4 & $12,6^{(4)}$ & 18,3 & 13,7 & $11,6^{(4)}$ & 15,6 & 11,2 \\
\hline Rumanía & 22,5 & 15,9 & 17,3 & 23,6 & 15,9 & 18,6 & 21,5 & 16,0 & 16,0 \\
\hline Suecia & $9,2^{(3)}$ & 7,9 & 7,1 & $10,2^{(3)}$ & 9,0 & 7,9 & $8,1^{(3)}$ & 6,8 & 6,2 \\
\hline \multicolumn{10}{|c|}{ Otros Países Europeos } \\
\hline Islandia & $20,3^{(4)}$ & 24,4 & 20,5 & $23^{(4)}$ & 26,2 & 24,4 & $17,4^{(4)}$ & 22,4 & 16,4 \\
\hline Noruega & $6,3^{(4)}$ & 17,0 & 13,7 & $7,7^{(4)}$ & 21 & 15,7 & $5^{(4)}$ & 12,9 & 11,6 \\
\hline Suiza & $9,7^{(4)}$ & 7,7 & 5,4 & $10,4^{(4)}$ & 7,8 & 5,6 & $9,1^{(4)}$ & 7,5 & 5,2 \\
\hline
\end{tabular}

(1) Indicador utilizado como punto de referencia general de la Estrategia 2020 de los sistemas educativos y formativos en la UE.

(2) Debido a la implementación de conceptos y definiciones armonizadas y/o a la transición a los nuevos cálculos realizados con las medias anuales, estos datos no coinciden con los publicados con anterioridad a noviembre de 2009.

(3) La definición del indicador difiere para estos datos.

(4) Ruptura de serie.

(5) Datos provisionales.

(6) Datos con problemas de fiabilidad. Fuente: Labour Force Survey (Encuesta Europea de Población Activa). Media anual. Eurostat.

Fuente: Ministerio de Educación, Cultura y Deporte, 2015a, http://www.mecd.gob.es/dms/ $\mathrm{mecd} /$ servicios-al-ciudadanomecd/estadisticas/educacion/indicadores-publicaciones-sintesis/ cifras-educacion-espana/2015/H1.pdf 
Gráfico 4. Tasa de empleo y desempleo y nivel de formación de la población de 25 a 64 años (2013)

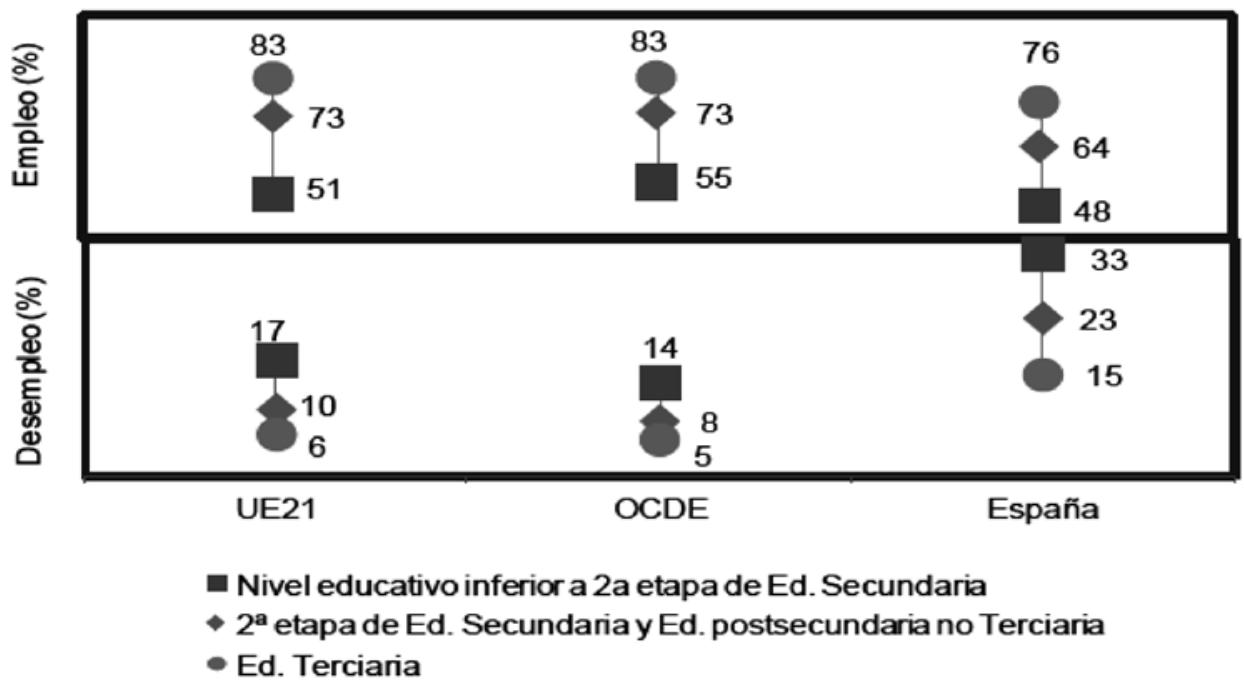

Fuente. Ministerio de Educación, Cultura y Deporte, 2015b, p.3.

Gráfico 5. Ingresos relativos de la población que percibe rentas de trabajo (2012 o año de referencia indicado)

Por nivel de formación de la población de 25 a 64 años

(segunda etapa de Educación Secundaria $=100$ )

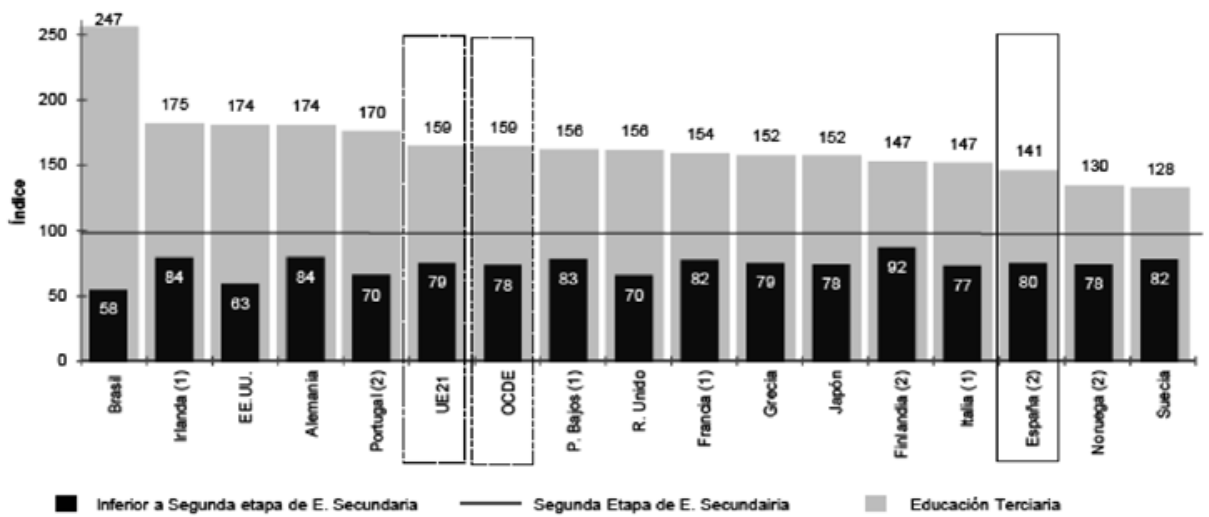

(1) Datos año 2010. (2) Datos año 2011.

Nota: Los paises están clasificados en orden descendente de los ingresos relativos de las personas de 25 a 64 años con Educación Terciaria.

Fuente: Ministerio de Educación, Cultura y Deporte, 2014, p.29. 
Ante esta situación es conveniente buscar qué provoca este abandono, cómo se puede seguir disminuyendo y en qué medida las políticas que hasta ahora se están aplicando son adecuadas; de hecho, la educación debe cumplir una función inclusiva y no se debe permitir que existan personas que no lleguen a tener una educación básica o que, por cuestiones económicas, tengan que abandonar la formación. En este sentido, el sector público de cada Estado de la Unión, a través de ayudas financieras (especialmente becas) tiene un papel fundamental para evitar, como mínimo, los posibles abandonos escolares producidos por factores económicos.

\subsubsection{Adaptar la educación y la formación a las necesidades reales del mercado laboral}

En algunos países de la Unión se está produciendo un importante desajuste entre la formación adquirida y las necesidades que hay en el mercado laboral, lo que está afectando especialmente a los jóvenes, quienes ven reducidas sus posibilidades de acceso a este mercado.

Los niveles de paro de los jóvenes entre 15 y 24 años que desean incorporarse al mercado laboral alcanzan en algunos países de la Unión cifras realmente preocupantes. Como se puede observar en el Gráfico 5, a finales del año 2014, la media del paro juvenil en la Unión Europea era del 21,3\%\% pero países como Chipre $(33,7 \%)$, Portugal (34\%), Italia (43,3\%), Croacia (50,1\%), Grecia (51.5\%) o España $(51,8 \%)$ presenta cifras muy superiores a esta media.

Gráfico 6. Tasa de paro juvenil en la Unión Europea (IV trimestre 2014) Edad 15-24 años

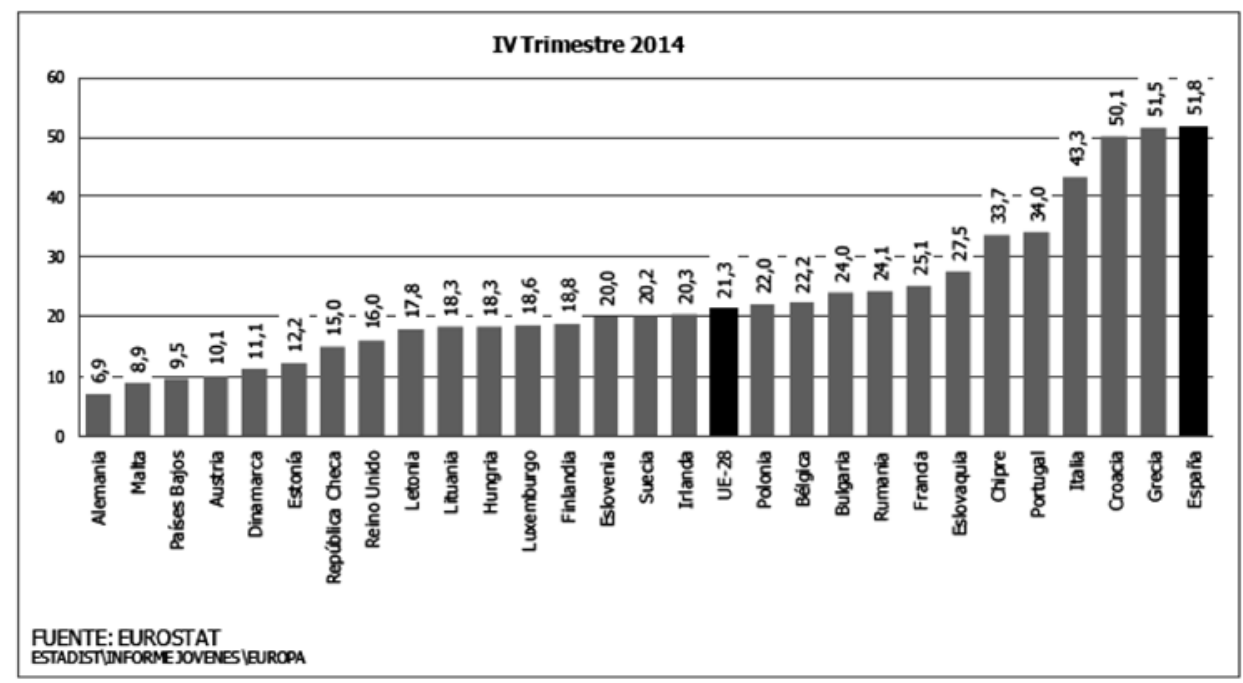

Fuente: Ministerio de Empleo y Seguridad Social, 2015, p 8. 
La Unión Europea ya ha puesto en marcha programas específicos para que la educación y la formación capacite a los individuos para acceder en mejores condiciones al mercado laboral y ha establecido mecanismos concretos para dar más información sobre las posibilidades de empleo existentes (por ejemplo, la Plataforma EURES ${ }^{15}$ o la iniciativa de empleo juvenil $\left.{ }^{16}\right)$; sin embargo, esto puede ser claramente insuficiente si no se produce una adecuada información sobre la existencia de estas nuevas posibilidades, especialmente entre los jóvenes. Las campañas de promoción de estos programas parecen insuficientes y debería replantearse la necesidad de mejorar la difusión de estas iniciativas para que se conozca mejor en qué consisten y qué hay que hacer.

Por otro lado, para que estas medidas sean realmente efectivas sería aconsejable acercar la formación a las necesidades de la empresa y de las diversas instituciones públicas y privadas.

Por último, es necesario buscar y aplicar nuevas medidas contra el fenómeno de los jóvenes que "ni estudia ni trabaja" (NEET en inglés) ya que están aumentando de forma considerable en todos los países (OCDE, 2015, pp. 33-35), lo que conlleva una infrautilización el capital humano que se haya podido generar, una pierda el capital financiero invertido y una reducción de las posibilidades de generar capital social.

\subsubsection{Incrementar los niveles de formación continua}

Aunque la Unión Europa, dentro de su estrategia Europa 2020, ha dejado clara la necesidad de que la población en edad de trabajar participe en formación continua, la realidad es que en muchos países esto no se fomenta adecuadamente.

Parece evidente la necesidad de mantener durante toda la vida laboral actualizado el capital humano adquirido en las primeras fases; sin embargo, para lograr esto el individuo debe de disponer de suficientes mecanismos fácilmente accesibles y compatibles con su posible actividad laboral.

Además, de facilitar la accesibilidad es fundamental tener en cuenta la calidad de esta formación continua ya que lo que realmente beneficia al individuo y a la sociedad es disponer de una formación que permita disponer de más posibilidades para mantenerse en el mercado laboral, e incluso, de reincorporarse al mismo en caso de haberlo perdido o no haberse incorporado nunca.

Por último, si existe un adecuado nivel de formación continua de calidad se podrán reducir los problemas de paro estructural existente en algunos mercados laborales europeos y que se agudizan en momentos de crisis económicas, lo que hará más factible amortiguar las posibles caídas de empleo y renta que se suelen producir en estas situaciones, disminuyendo el efecto social negativo que pudiera aparecer durante la crisis.

\footnotetext{
${ }^{15}$ https://ec.europa.eu/eures/public/es/homepage

${ }^{16} \mathrm{http} / / /$ ec.europa.eu/social/main.jsp?catId=1176\&langId=es
} 
3.2.4. Equilibrar el nivel de la investigación, el desarrollo y la innovación en la Unión

Si bien gracias a la Estrategia de Lisboa y a la estrategia Europa 2020 la investigación, el desarrollo y la innovación han cobrado más importancia en el ámbito de la Unión, en la práctica, todavía existen importantes diferencias entre unos países y otros.

Cuando se habla de la investigación y desarrollo, los creadores de conocimiento, el primer aspecto que se suele plantear es el alto coste que conlleva disponer de unas instalaciones adecuadas para llevarlas a cabo (especialmente en la investigación básica) pero, como segundo factor fundamental, se plantea la necesidad de establecer un adecuado sistema de becas y ayudas que permitan dar una estabilidad financiera al investigador durante todo el tiempo que pueda requerir para la investigación, desarrollo y la posterior innovación.

\section{Cuadro 3. Gasto en I+D (\% PIB) por país. 2002-2014}

\begin{tabular}{|c|c|c|c|c|c|c|c|c|c|c|c|c|c|}
\hline & 2002 & 2003 & 2004 & 2005 & 2006 & 2007 & 2008 & 2009 & 2010 & 2011 & 2012 & 2013 & 2014 \\
\hline $\begin{array}{l}\text { EU } \\
\text { ( } 28 \text { páses) }\end{array}$ & 1,81 & 1,80 & 1,76 & 1,76 & 1,78 & 1,78 & 1,85 & 1,94 & 1,93 & 1,97 & 2,01 & 2,03 & 2,03 \\
\hline Alemania & 2,42 & 2,46 & 2,42 & 2,43 & 2,46 & 2,45 & 2,60 & 2,73 & 2,72 & 2,80 & 2,88 & 2,83 & 2,84 \\
\hline Austria & 2,07 & 2,18 & 2,17 & 2,38 & 2,37 & 2,43 & 2,59 & 2,61 & 2,74 & 2,68 & 2,81 & 2,96 & 2,99 \\
\hline Bélgica & 1,89 & 1,83 & 1,81 & 1,78 & 1,81 & 1,84 & 1,92 & 1,97 & 2,05 & 2,15 & 2,24 & 2,42 & 2,46 \\
\hline Bulgaria & 0,47 & 0,47 & 0,48 & 0,45 & 0,45 & 0,44 & 0,46 & 0,51 & 0,59 & 0,55 & 0,62 & 0,65 & 0,80 \\
\hline Chipre & 0,28 & 0,32 & 0,34 & 0,37 & 0,39 & 0,40 & 0,39 & 0,45 & 0,45 & 0,46 & 0,43 & 0,46 & 0,47 \\
\hline Croacia & 0,95 & 0,95 & 1,03 & 0,86 & 0,74 & 0,79 & 0,88 & 0,84 & 0,74 & 0,75 & 0,75 & 0,81 & 0,79 \\
\hline Dinamarca & 2,44 & 2,51 & 2,42 & 2,39 & 2,40 & 2,51 & 2,78 & 3,07 & 2,94 & 2,97 & 3,03 & 3,08 & 30,8 \\
\hline Eslovaquia & 0,56 & 0,56 & 0,50 & 0,49 & 0,48 & 0,45 & 0,46 & 0,47 & 0,62 & 0,67 & 0,81 & 0,83 & 0,89 \\
\hline Eslovenia & 1,44 & 1,25 & 1,37 & 1,41 & 1,53 & 1,42 & 1,63 & 1,82 & 2,06 & 2,43 & 2,58 & 2,60 & 2,39 \\
\hline España & 0,96 & 1,02 & 1,04 & 1,10 & 1,17 & 1,23 & 1,32 & 1,35 & 1,35 & 1,32 & 1,27 & 1,24 & 1,20 \\
\hline Estonia & 0,72 & 0,77 & 0,85 & 0,92 & 1,12 & 1,07 & 1,26 & 1,40 & 1,58 & 2,34 & 2,16 & 1,74 & 1,46 \\
\hline Finlandia & 3,26 & 3,30 & 3,31 & 3,33 & 3,34 & 3,35 & 3,55 & 3,75 & 3,73 & 3,64 & 3,43 & 3,30 & 3,17 \\
\hline Francia & 2,17 & 2,11 & 2,09 & 2,04 & 2,05 & 2,02 & 2,06 & 2,21 & 2,18 & 2,19 & 2,23 & 2,24 & 2,26 \\
\hline Grecia & - & 0,55 & 0,53 & 0,58 & 0,56 & 0,58 & 0,66 & 0,63 & 0,60 & 0,67 & 0,69 & 0,80 & 0,83 \\
\hline Hungría & 0,99 & 0,92 & 0,87 & 0,93 & 0,99 & 0,97 & 0,99 & 1,14 & 1,15 & 1,20 & 1,27 & 1,41 & 1,38 \\
\hline Irlanda & 1,06 & 1,13 & 1,18 & 1,20 & 1,21 & 1,24 & 1,39 & 1,63 & 1,62 & 1,53 & 1,58 & 1,58 & 1,55 \\
\hline Italia & 1,08 & 1,06 & 1,05 & 1,05 & 1,09 & 1,13 & 1,16 & 1,22 & 1,22 & 1,21 & 1,26 & 1,30 & 1,29 \\
\hline Letonia & 0,41 & 0,36 & 0,40 & 0,53 & 0,65 & 0,56 & 0,58 & 0,45 & 0,60 & 0,70 & 0,66 & 0,60 & 0,68 \\
\hline Lituania & - & - & 0,75 & 0,75 & 0,79 & 0,80 & 0,79 & 0,83 & 0,78 & 0,90 & 0,90 & 0,95 & 1,02 \\
\hline Luxemburgo & - & 1,65 & 1,63 & 1,59 & 1,69 & 1,65 & 1,65 & 1,72 & 1,50 & 1,41 & 1,16 & 1,31 & 1,24 \\
\hline Malta & 0,25 & 0,24 & 0,49 & 0,53 & 0,58 & 0,55 & 0,53 & 0,52 & 0,64 & 0,70 & 0,87 & 0,85 & 0,85 \\
\hline Países Bajos & 1,77 & 1,81 & 1,82 & 1,81 & 1,77 & 1,70 & 1,65 & 1,69 & 1,72 & 1,89 & 1,97 & 1,96 & 1,97 \\
\hline Polonia & 0,56 & 0,54 & 0,56 & 0,57 & 0,55 & 0,56 & 0,60 & 0,67 & 0,72 & 0,75 & 0,89 & 0,87 & 0,94 \\
\hline Portugal & 0,72 & 0,70 & 0,73 & 0,76 & 0,95 & 1,12 & 1,45 & 1,58 & 1,53 & 1,46 & 1,37 & 1,33 & 1,29 \\
\hline Reino Unido & 1,72 & 1,67 & 1,61 & 1,63 & 1,65 & 1,69 & 1,69 & 1,75 & 1,69 & 1,69 & 1,63 & 1,69 & 1,72 \\
\hline R. Checa & 1,10 & 1,15 & 1,15 & 1,17 & 1,23 & 1,31 & 1,24 & 1,30 & 1,34 & 1,56 & 1,79 & 1,91 & 2,00 \\
\hline Rumanía & 0,38 & 0,38 & 0,38 & 0,41 & 0,45 & 0,52 & 0,57 & 0,46 & 0,45 & 0,49 & 0,48 & 0,39 & 0,38 \\
\hline Suecia & - & 3,61 & 3,39 & 3,39 & 3,50 & 3,26 & 3,50 & 3,42 & 3,22 & 3,22 & 3,28 & 3,30 & 3,16 \\
\hline
\end{tabular}

Fuente: http://www.eustat.eus/elementos/ele0003200/ti_Gasto_en_ID_PIB_por_pais19962008/tbl0003292_c.html\#axzz3s7kLT6U5. (Fecha de consulta 1 de octubre 2015). 
Si se observa el Cuadro 3 se puede comprobar la gran diferencia existente entre los distintos países de la Unión Europea en cuanto al Porcentaje del PIB que dedican al Gasto en I+D. Aunque en la Estrategia 2020 se haya establecido como uno de los objetivos llegar a un gasto en I+D del 3\% del PIB (Comisión Europea, 2010, p. 5), el esfuerzo que se está realizando en el área de I+D está siendo claramente insuficiente en muchos países. En este sentido, algunas naciones de la Unión tienen todavía un gran camino que recorrer que difícilmente se emprenderá de forma adecuada si no se toma conciencia, por parte de las autoridades, de que este Gasto Público es una Inversión para el futuro y, en consecuencia, se debe hacer un análisis coste-beneficio que incluya nuevas variables relacionadas con los efectos beneficiosos, directos e indirectos, que se pueden alcanzar tanto a nivel económico como social con este tipo de gasto.

De momento, a nivel europeo se están fomentado diversos cambios legislativos y favoreciendo la colaboración entre investigadores pero todavía es necesario consolidar la importancia que tienen el I+D para poder crear el tipo de economía y sociedad que la UE desea para un futuro.

Para ello resulta fundamental que, por lo menos, se tenga en cuenta tres cuestiones; a) si se desean producciones competitivas, es necesario investigar en nuevos productos, nuevos mercados o nuevas formas de gestión; b) si se quiere mantener el estado de bienestar, hay que investigar nuevas formas de gestión pública que permitan tener una Hacienda Pública que pueda cumplir sus funciones fundamentales de forma eficaz y eficiente y c) si el objetivo es alcanzar sociedades inclusivas y respetuosas con el entorno se necesitan investigar, desarrollar e innovar nuevos mecanismo para lograr un desarrollo económico en donde estos factores sean tenidos en cuenta.

Además de lo expuesto, conviene recordar que la investigación puede ser muy variada pero lo importante es que se desarrolle y que se aplique a la realidad a través de la innovación. Para lograr esto, es primordial que se amplíen las posibilidades de colaboración con empresas e instituciones públicas y privadas lo que se ve claramente favorecido si:

- las autoridades de cada país establecen un marco legal seguro para todas las partes implicadas en dicha colaboración. Por ejemplo, fortalecer la regulación de patentes, mejorar la lucha contra las imitaciones de nuevas producciones o apoyar la difusión de la investigación y la innovación;

- se logra una participación activa de todas las partes implicadas, tanto en el proceso de investigación como en el de desarrollo e innovación;

- se realiza una adecuada distribución de costes y beneficios entre todas las partes implicadas.

Dadas las diferencias actualmente existentes en los países de la Unión en relación con el $\mathrm{I}+\mathrm{D}+\mathrm{i}$ se puede afirmar que todavía queda mucho por hacer, tanto a 
nivel global como en los diversos Estados miembros, pero lo importante es que el proceso se ha iniciado y es fundamental que continúe en el futuro con independencia de los movimientos que se puedan producir en las economías.

\subsection{En conclusión}

Por las medidas aplicadas en las últimas estrategias europeas parece claro que la Unión Europea se ha dado cuenta del papel que tiene la educación, la formación y la investigación, el desarrollo y la innovación para más aspectos económicos de los que tradicionalmente se destacaban.

Actualmente se reconoce el valor que tienen en el desarrollo económico, crecimiento económico, la estabilidad en el mercado laboral y el efecto beneficioso sobre inclusión social; sin embargo, todavía quedan algunos efectos económicos poco valorados y que convendría considerar ya que permitirían dar un papel más importante a la Política de educación y formación y a la Política de I+D+i dentro de las Políticas Económicas de los países, tanto a nivel general de la Unión como de sus países miembros.

\section{LA EDUCACIÓN DE CALIDAD COMO MECANISMO ANTICRISIS ECONÓMICAS}

Por un lado, a lo largo de este estudio se ha puesto de manifiesto que la educación y formación son mucho más que un derecho social; de hecho, no se puede dudar que es la base para lograr que en el futuro existan países capaces de alcanzar un desarrollo económico sostenible e inclusivo y respetuoso desde el punto de vista ambiental, gracias a una adecuada evolución en el capital humano, tecnológico y social. Por otro lado, una adecuada investigación, desarrollo e innovación es lo que puede permitir que este tipo de desarrollo se pueda mantener a lo largo del tiempo dado que favorece una mayor capacidad para ajustarse a los diversos cambios socioeconómicos que se puedan producir.

De lo anteriormente expuesto surge un nuevo aspecto relacionado con la educación y el $\mathrm{I}+\mathrm{D}+\mathrm{i}$ que no se suele tener en cuenta y que, sin embargo, es fundamental. Una educación y formación de calidad y un alto y consolidado nivel de investigación, desarrollo e innovación permiten a las naciones afrontar de una manera menos traumática las crisis económicas, con independencia del origen de las mismas, ya que reduce la vulnerabilidad socioeconómica de las naciones. Las principales razones que justifican este hecho son:

1. La educación y formación favorece la inclusión social al permitir disponer de más oportunidades para adaptarse al mercado laboral, e incluso, capacita 
al individuo para actuar como emprendedor o autónomo. Cuanto más se adapte esa educación a las necesidades existentes en la sociedad; más calidad tenga; más capacitado esté el individuo en determinadas habilidades (comunicación escrita y oral, iniciativa, trabajo en grupo,...) y mejores sean sus conocimientos en las materias fundamentales, más oportunidades puede tener para adaptarse a los cambios que se presenten en el ámbito económico y existirá menos probabilidades de estar en riesgo de una exclusión social.

La educación, además de aportar conocimiento, debe fomentar capacidades y habilidades que permitan un completo desarrollo humano y, entre estas habilidades, deben estar también las de interrelación con los demás, lo que permite fomentar tanto el capital humano como el capital social. Las personas con mejor preparación académica y laboral que dispongan de más flexibilidad frente a otras culturas o posiciones y con mayor capacidad de adaptación a los problemas son, sin duda, las más eficaces para solventar tensiones y solucionar los diversos problemas que se puedan presentar en una crisis económica. En esta línea, se considera fundamental que se solucionen los problemas de abandono escolar, el desajuste existente entre la educación y formación y los requerimientos del mercado laboral, así como, las posibles deficiencias en la calidad de la enseñanza. Si esto no se soluciona, las futuras generaciones pueden ser excesivamente vulnerables a alteraciones en el mercado laboral y si, además, carecen de movilidad funcional o geográfica pueden producirse situaciones de paro excesivamente elevadas, que pueden afectar negativamente a; la demanda, sobre todo al consumo; a la oferta, vía demanda y por pérdida de productividad del factor trabajo y, en consecuencia, al nivel renta; por último, esta situación también afectará tanto a los gastos como a los ingresos de las Administraciones Públicas influyendo en su capacidad real de actuación. Todo esto dificultaría el adecuado desarrollo tanto del sector privado como público de la nación.

Como se puede observar, no solucionar algunos problemas existentes en el ámbito educativo, además de impedir que los individuos puedan afrontar mejor las crisis económicas, puede ser generador de las mismas lo que exige plantearse más adecuadamente las medidas que se aplican. Sabiendo donde pueden estar estos problemas resulta primordial, desde el punto de vista económico, intentar solucionarlos y preparar a los individuos para un contexto que puede cambiar en cualquier momento. Esto permitirá que las próximas generaciones puedan adaptarse mejor a situaciones de recesión y que los efectos sociales negativos que tiene una crisis económica sean menores.

2. La formación continua es fundamental para afrontar los cambios que se puedan producir en el ámbito económico. Por su propia naturaleza, todas las sociedades cambian con el tiempo y esas alteraciones en el comportamiento de los individuos o en las relaciones sociales provocan efectos en el contexto en el que se mueven los distintos agentes económicos. 
La educación se adquiere en un contexto y con unos conocimientos determinados pero, evidentemente, estos cambiaran con los años, de ahí la importancia de educar destacando la necesidad del aprendizaje continuo.

Los individuos, con independencia de la situación socioeconómica en la que se encuentren, deben de adaptarse a los cambios sociales y a lo que esto conlleva en el ámbito económico, por ejemplo, con el tiempo surgirán nuevas formas de consumir, de invertir, de gestionar, de producir o de comunicar. La formación continua de calidad facilita disponer de una mayor capacidad para adaptarse a estos cambios, e incluso, puede ser uno de los factores para sacar el mayor provecho de los mismos.

En caso de no estar preparado para el nuevo contexto económico que se esté configurando, algunos agentes económicos (especialmente trabajadores y empresarios, sobretodo pymes) pueden quedar excluidos del ámbito económico lo que afectará negativamente tanto al mercado laboral como al nivel productivo del país. Sin embargo, si los agentes económicos disponen de una formación continua adecuada pueden adaptarse al nuevo contexto existente y continuar o mejorar su posicionamiento anterior logrando convertir lo que sería un problema en una ventaja.

3. Los países necesitan desarrollar sus conocimientos, creando nuevas líneas de actuación que permitan mantener el desarrollo económico teniendo en cuenta los recursos de los que se dispone. No se duda de la necesidad de la investigación en todos los ámbitos y de la creación de nuevos conocimientos en todas las áreas; sin embargo lo más importante es que esas investigaciones se puedan desarrollar y que se pase a la innovación.

Si se desea ser un área geográfica independiente en conocimientos del exterior es fundamental potenciar a nivel interno la investigación, el desarrollo y la innovación. Una cuestión es colaborar con otras áreas en el intercambios de innovaciones y otra, muy distinta, es depender de ellas para seguir avanzando económicamente.

La sostenibilidad de una economía implica desarrollar I+D+i; de hecho, si se tiene una sólida estructura ya establecida en estos factores, las probabilidades de poder afrontar adecuadamente ciertas tensiones económicas son mayores, en especial, cuando se producen profundas crisis económicas que afectan tanto al lado de la demanda como de la oferta agregada, al lado real y al financiero y que son generalmente internacionales. En estas situaciones es necesario disponer de antemano de una buena base investigadora, que tenga facilidad para poder desarrollarse y que esté acostumbrada a la innovación, lo que permitiría generar nuevas alternativas que aportasen soluciones para evitar los graves deterioros sociales que se suelen producir en momentos de graves crisis económicas. 
Desde el punto de vista expuesto, aunque siga siendo importante el análisis cuantitativo es fundamental establecer un análisis cualitativo de cómo avanza la calidad en la educación, la formación y en I+D+i. Mejorar la calidad es fundamental pero para conseguirlo es necesario, en muchos casos, disponer de unos fondos financieros que las Administraciones Públicas no siempre tienen o pueden obtener. En este sentido, se ha observado que en demasiadas ocasiones las Administraciones tienden a quitar importancia y recursos a la mejora de la calidad sin tener en cuenta el grave error cometido. Es necesario que no se olvide que solo con una educación, formación e I+D de calidad se conseguirá una sociedad más flexible y preparada para afrontar cualquier cambio del entorno y que, por tanto, cualquier reducción del apoyo para el fomento de la calidad tendrá unos efectos futuros negativos cuyo alcance no es siempre fácil de determinar pero que habrá que asumir.

Sin poner en duda la falta de recursos que tienen las Administraciones Públicas, las obligaciones que existen respecto a la cobertura de otros gastos públicos y las posibles limitaciones en cuanto a ingresos, es necesario reflexionar sobre cuánto, cómo y dónde se gasta en educación y formación y en $\mathrm{I}+\mathrm{D}+\mathrm{i}$ ya que la importancia que tienen estas cuestiones tanto a largo como a medio y corto plazo exige un replanteamiento respecto al papel que se les da. Además de plantearse cuánto se ha gastado, si lo que se desea es alcanzar una determinada calidad, es importante analizar dónde y cómo se ha producido el gasto:

- En educación debe de existir una adecuada distribución de los recursos y un mayor control de la utilización de los mismos. Se debe de incentivar la colaboración entre las Administraciones Públicas y las entidades privadas relacionadas con el ámbito educativo en cuanto a contenido académico, habilidades a desarrollar o sistemas de ayudas. Sin embargo, lo que no se debe incentivar son posibles diferencias regionales o sociales por el tipo o la calidad de la educación recibida o por una excesiva diferencia en la infraestructura disponible en los centros educativos.

La colaboración se debe producir para aumentar la calidad y contribuir en toda la sociedad no para aumentar diferencias sociales, por eso dicha colaboración implica tener la garantía con respecto a que los contenidos e infraestructuras van a ser similares en cualquier ámbito regional y entorno social.

No se puede impedir la existencia de educación privada pero si ésta accede a una parte de los fondos públicos disponibles se debe exigir el cumplimiento de unos mínimos que garanticen que la ayuda pública recibida se destinara a garantizar los mismos objetivos fundamentales que se tendrían con una educación pública.

- En el ámbito de la formación, además de implicarse las Administraciones Públicas, debe de existir mayor colaboración con las entidades privadas ya 


\section{Yolanda Fernández Jurado}

que éstas pueden ser las más beneficiadas al mantener y aumentar el capital humano que tienen o al que pueden acceder. En este sentido resulta de interés la colaboración que puede desarrollarse entre el ámbito empresarial y las entidades de educación superior, universitaria y no universitaria.

- Si realmente se desea establecer una adecuado nivel de I+D+i en determinadas áreas geográficas, en este caso la Unión Europea, la colaboración entre empresas, centros de investigación y Administraciones es fundamental. La investigación necesita recursos financieros, recursos humanos y determinadas infraestructuras, sobretodo en el caso de la investigación básica, y en la mayoría de los casos tiene un objetivo claro: crear capacidad de innovar. El coste que conlleva todo el proceso hasta la innovación hace necesario que se impliquen distintos agentes; las administraciones pueden dotar de instalaciones, dar apoyo financiero o aportar capital humano; los centros de investigación pueden aportar el capital humano y los contactos de los que dispongan para desarrollar la investigación y, por último, las entidades privadas además de todo lo anterior pueden permitir la innovación como punto final de la investigación realizada.

De esta forma, con la implicación de diversos agentes económicos, se puede obtener una investigación de calidad, con opciones a desarrollarse y con muchas posibilidades de generar innovaciones que permitan avanzar a la sociedad en todos sus aspectos.

Si existe una buena calidad en educación, en formación y en $\mathrm{I}+\mathrm{D}+\mathrm{i}$ cualquier crisis que se produzca en el ámbito socioeconómico puede analizarse y superarse mejor a corto, medio y largo plazo dado que las posibilidades de encontrar nuevas alternativas a la situación de recesión son mucho mayores y más rápidas, lo que fortalece las perspectivas económicas y sociales de cualquier nación y permite paliar, con cierta rapidez, algunos de los efectos negativos generados por la crisis.

Teniendo en cuenta lo expuesto, se puede afirmar que la educación y la formación, especialmente la de calidad, junto la $\mathrm{I}+\mathrm{D}+\mathrm{i}$ pueden ser buenos amortiguadores de crisis económicas, lo que las dota de un gran valor para superar mejor situaciones en las que se producen fuertes deterioros económicos que pueden generar importantes desequilibrios sociales.

\section{CONCLUSIONES}

A lo largo de este análisis se ha puesto de manifiesto que no conviene considerar la educación, la formación y la investigación, el desarrollo y la innovación como unas políticas socioeconómicas que tienen cierta importancia pero que, llegado un momento de crisis, pueden pasar a segundo plano. 
La Política educativa y de formación y la Política de I+D+i son políticas fundamentales desde el punto de vista económico ya que son las que realmente desarrollan económicamente un país (generan el capital humano, capital social y capital tecnológico) y permiten sociedades más inclusivas y respetuosas con el medioambiente pero, también hay que tener en cuenta que facilitan amortiguar los efectos negativos que se generan en situaciones de crisis económicas tanto en el ámbito económico (por ejemplo, disminución del empleo o caída en la renta) como social (por ejemplo, el posible aumento de pobreza y exclusión social) y, además, permiten a las naciones aprovechar mejor todas las posibilidades que se ofrecen en épocas de auge.

En definitiva, considerar estas políticas en un segundo plano desde el punto de vista económico es una posición sobre la que hay que reflexionar seriamente ya que, en realidad, son la base de muchas otras política económicas. De hecho, cualquier actuación económica coyuntural o estructural, parcial o global, nacional o internacional, individual o colectiva, pública o privada, parte del conocimiento teórico o práctico existente, de cómo se transmite y de cómo avanza. Esto convierte a la educación, la formación y la investigación, desarrollo e innovación en unos de los pilares fundamentales del futuro económico de las naciones y, en consecuencia, así se las debería considerar.

Para lograr esto, conviene complementar la tradicional visión de la Política de educación y de formación como política a largo plazo con un correcto estudio de su evolución en el medio y corto plazo (eso último cobra especial interés en el caso de la formación continua y la profesional). Es necesario analizar en profundidad el cómo, cuándo, por qué, dónde y para quién se establece una política educativa y formativa, porque eso es lo que permitirá determinar con más claridad cómo lograr unos determinados niveles de calidad en todas las etapas; garantizar la igualdad de oportunidades con independencia del territorio o nivel de renta que tengan los individuos y crear una sociedad con mayor capacidad de respuesta ante posibles alteraciones en el entorno social o económico.

Por último, es conveniente recordar que las diversas modificaciones que se puedan realizar deben caracterizarse por tener una continuidad en el tiempo con el objetivo de maximizar los recurso utilizados, lo que no impide que existan indicadores de control que indiquen la necesidad de realizar ciertos ajustes si se observa una inadecuada evolución en los objetivos establecidos. Deben tomarse decisiones claras de hacia dónde se desea avanzar, crear mecanismos de flexibilidad para adaptarse a los cambios reales que se presenten o que puedan influir en la senda prevista y, sobretodo, no hay que olvidar que tan importante como el volumen del gasto realizado es la adecuada distribución del mismo, ya que con esto es con lo que se podrán alcanzar todos los beneficios que se pueden obtener con una educación, formación e I+D de calidad. Si esto no se tiene en cuenta, lo que se habrá producido es una pérdida de recursos totalmente ilógica en un contexto en el que éstos son escasos. 


\section{BIBLIOGRAFÍA}

ANGHEL, B., ANTONIO CABRALES y JESÚS M. CARRO (2013), Evaluación de un programa de educación bilingüe en España: El impacto más allá del aprendizaje del idioma extranjero. Madrid: FEDEA. Fundación de Estudios de Economía Aplicada. Disponible en http://www.fedea.net (consulta septiembre 2015).

COMISIÓN DE LAS COMUNIDADES EUROPEAS (2003), «Educación y Formación 2010» urgen las reformas para coronar con éxito la Estrategia de Lisboa COM(2003) 685 final Bruselas,11.2003. Disponible en: https://www.sepe.es/contenidos/personas/formacion/refernet/pdf/ com_2003_685a1_23013_es.pdf11 (consulta septiembre 2015).

COMISIÓN EUROPEA (2010), Europa 2020. Una estrategia para un crecimiento inteligente, sostenible e integrador, COM (2010) 2020. Bruselas., 3.3.2010. Disponible en: http://eur-lex.europa.eu/LexUriServ/LexUriServ.do?uri=COM:2010:2020: FIN: ES: PDF (consulta agosto 2015).

COMISIÓN EUROPEA (2011), Progress towards the common European objectives in education and training. Indicators and benchmarks. Annual progress report 2010/2011. Disponible en: http://ec.europa.eu/education. (consulta septiembre 2015).

COMISIÓN EUROPEA (2013), Horizonte 2020. El Programa Marco de Investigación e Innovación (2014-2020). Bruselas: Diario Oficial de la Unión Europea 20-12-2013. L 347/104 a L347/173.

COMISIÓN EUROPEA (2014), Income distribution statistics. Disponible en: http://epp.eurostat.ec.europa.eu/statistics_explained/index.php/Income_ distribution_statistics (consulta noviembre 2015)

COMISIÓN EUROPEA (2015), Education and Training Monitor 2014, http:// ec.europa.eu/education/tools/docs/2014/monitor2014-es_en.pdf. (consulta septiembre 2015).

CONSEJO DE EUROPA (1961), Carta Social Europea, Turín, 18 de octubre, Disponible en http://www.acnur.org/t3/fileadmin/scripts/doc. php?file=t3/fileadmin/Documentos/BDL/2002/1934 (consulta septiembre 2015)

CONSEJO EUROPEO (2003), Niveles de referencia del rendimiento medio europeo en educación y formación (Puntos de referencia). Conclusiones del Consejo de 5 de mayo de 2003, Diario Oficial 2003/C 134/02.

CONSEJO EUROPEO (2007), Marco coherente de indicadores y puntos de referencia para el seguimiento de los avances hacia los objetivos de Lisboa en el ámbito de la educación y la formación. Conclusiones del Consejo de 25 de mayo de 2007, Diario Oficial 2007/C 311/10. 
CONSEJO EUROPEO (2009), Marco estratégico para la cooperación europea en el ámbito de la educación y la formación (ET 2020). Conclusiones del Consejo de 12 de mayo de 2009, Diario Oficial de la Unión 2009/C $119 / 02-119 / 10$.

DE LA FUENTE, A. y JIMENO, J. F. (2011), La rentabilidad privada y fiscal de la educación en España y sus regiones, Documento de Trabajo 2011-11. FEDEA, Fundación de Estudios de Economía Aplicada.

http://www.iae.csic.es/investigatorsMaterial/a12124084154archivoPdf41232.pdf (consulta septiembre 2015)

DIARIO OFICIAL DE LA UNIÓN EUROPEA (2010), Carta de los Derechos Fundamentales de la Unión Europea (2010/C 83/02). C 83/389- C 83/403.

EUROSTAT (2010), Europe 2020 Indicators. Disponible en http://epp.eurostat.ec.europa.eu/ (consulta octubre 2015)

JUNCKER, J. C. (2014), A New Start for Europe: My Agenda for Jobs, Growth, Fairness and Democratic Change, Strasbourg, 15 July 2014.

MINISTERIO DE EDUCACIÓN, CULTURA Y DEPORTE (2013), Objetivos educativos europeos y españoles. Estrategia Educación y Formación 2020. Informe Español 2013 Disponible en: http://www.mecd.gob.es. (consulta septiembre 2015)

MINISTERIO DE EDUCACIÓN, CULTURA Y DEPORTE (2014), Panorama de la educación indicadores de la OCDE 2014. Informe Español. Disponible en: www.mecd.gob.es/...educativos/panorama2014/ panorama-de-la-educacion-2014informe-espanol-05-sep-.pdf. (consulta octubre 2015).

MINISTERIO DE EDUCACIÓN, CULTURA Y DEPORTE (2015a), Las cifras de la educación en España. Curso 2012-2013 (Edición 2015). Disponible en:

http://www.mecd.gob.es/servicios-al-ciudadano-mecd/estadisticas/educacion/indicadores-publicaciones-sintesis/cifras-educacion-espana/2015. html ver H1 (consulta noviembre 2015)

MINISTERIO DE EDUCACIÓN, CULTURA Y DEPORTE (2015b), Boletin de Educación, núm. 40, enero 2015, http://www.mecd.gob.es/inee (consulta noviembre 2015)

MINISTERIO DE EMPLEO Y SEGURIDAD SOCIAL (2014), Estrategia de Emprendimiento y Empleo Joven 2013-2016. Disponible en: http://www.empleo.gob.es/ficheros/garantiajuvenil/documentos/EEEJ_ Documento.pdf (consulta septiembre 2015)

MINISTERIO DE EMPLEO Y SEGURIDAD SOCIAL (2015), Análisis del Mercado de Trabajo de los Jóvenes, marzo 2015. Disponible en: http:// www.empleo.gob.es/es/sec_trabajo/analisis-mercadotrabajo/jovenes/ numeros/2015marzo/I.pdf (consulta septiembre 2015). 
MINISTROS EUROPEOS DE LA UE (1999), Declaración de Bolonia. Disponible en: http://eur-lex.europa.eu/legal-content/ES/TXT/ HTML/?uri=URISERV: c11088\& from=ES (consulta septiembre 2015).

OCDE (2012), Teaching in Focus, núm. 1. Disponible en http://www.oecd.org/ edu/school/ (consulta septiembre 2015).

OCDE (2013), “¿Cuál es el impacto de la crisis económica en el gasto público en educación?", Education Indicators in Focus, núm. 18. Disponible en: http://www.mecd.gob.es/dctm/inee/indicator-in-focus/ edif-2013--n18-esp.pdf?documentId=0901e72b819cf31d （consulta octubre 2015).

OCDE (2014), TALIS 2013 Results and International Perspective on Teaching and Learning, Disponible en: http://www.mecd.gob.es/dctm/inee/internacional/ talis2013/-talis-2014-eng--full-11-ebook.pdf?documentld=0901e72b819dbfd7 (consulta octubre 2015).

OCDE (2015), Education at a Glance Interim Report: Update of Employment and Educational Attainment Indicators. Disponble en http://www.oecd.org/edu/ EAG-Interim-report.pdf (consulta octubre 2015).

ONU (1948), Declaración Universal de Derechos Humanos, http://www.derechoshumanos.net/normativa/normas/1948-DeclaracionUniversal.htm. (consulta septiembre 2015).

ONU (1966), Pacto Internacional de Derechos Económicos, Sociales y Culturales. Disponible en http://www.ohchr.org/SP/ProfessionalInterest/Pages/ CESCR.aspx (consulta septiembre 2015).

ONU (2015). Resolución Aprobada por la Asamblea General 25 de septiembre 2015. A/Res/70/1. 21 de octubre 2015. http://www.un.org/ga/search/ view_doc.asp?symbol=A/RES/70/1\&referer=/english/\&Lang=S (consulta noviembre 2015).

PADILLA, R. V. (1999), "La formación de docentes para la educación bilingüe”, ponencia presentada en el Coloquio Internacional Search of a Border Pedagogy: Bilingualism and Professional Development in Schools, Adult Education and the Business, 20 - 23 de enero de 1999, El Paso y Ciudad Juárez. Disponible en: http://faculty.coehd.utsa.edu/rpadilla/currenttalks/jan99/ formaciondedocentes.html (consulta septiembre 2015).

PARLAMENTO EUROPEO (2000), Conclusiones de la Presidencia. Consejo Europeo de Lisboa, 23 y 24 marzo 2000, (Estrategia de Lisboa). Disponible en: http://www.europarl.europa.eu/summits/lis__es.htm (consulta septiembre 2015)

SEN, A. K. (2000), Desarrollo y Libertad. Buenos Aires: Editorial Planeta S. A. UNESCO (2014), Informe de Seguimiento de la EPT en el Mundo. El desarrollo sostenible empieza por la Educación. Cómo puede contribuir la educación a los objetivos propuestos después del 2015, http://en.unesco.org/gem-re- 
port/sustainable-development-begin education\#sthash.gcaoBr2K.dpbs. (consulta marzo 2014)

UNESCO y UIS (2015) Documento de Política 22 / Nota de información 31, Con una ayuda que no está a la altura de las circunstancias, un número creciente de niños y adolescentes queda sin escolarizar. http:// unesdoc.unesco.org/images/0023/002336/233610S.pdf (consulta octubre 2015) 
